Coexpression of Tyrosine Hydroxylase, GTP Cyclohydrolase I, Aromatic Amino Acid Decarboxylase, and Vesicular Monoamine Transporter 2 from a Helper Virus-Free Herpes Simplex Virus Type 1 Vector Supports High-Level, Long-Term Biochemical and Behavioral Correction of a Rat Model of Parkinson's Disease

\author{
MEI SUN ${ }^{1}$, LINGXIN KONG ${ }^{1}$, XIAODAN WANG ${ }^{1}$, COURTNEY HOLMES ${ }^{2}$, QINGSHENG \\ GAO $^{1}$, GUO-RONG ZHANG ${ }^{1}$, JOSEF PFEILSCHIFTER ${ }^{3}$, DAVID S. GOLDSTEIN ${ }^{2}$, and ALFRED \\ I. GELLER ${ }^{1}$ \\ 1 Department of Neurology, West Roxbury VA Hospital/Harvard Medical School, West Roxbury, \\ MA 02132.
}

2 Clinical Neurocardiology Section, National Institute of Neurological Disease and Stroke, Bethesda, MD 20892

3 Pharmazentrum Frankfurt, University Hospital, 60590 Frankfurt, Germany.

\begin{abstract}
Parkinson's disease is due to the selective loss of nigrostriatal dopaminergic neurons. Consequently, many therapeutic strategies have focused on restoring striatal dopamine levels, including direct gene transfer to striatal cells, using viral vectors that express specific dopamine biosynthetic enzymes. The central hypothesis of this study is that coexpression of four dopamine biosynthetic and transporter genes in striatal neurons can support the efficient production and regulated, vesicular release of dopamine: tyrosine hydroxylase (TH) converts tyrosine to L-3,4-dihydroxyphenylalanine ( $\mathrm{L}$-DOPA), GTP cyclohydrolase I (GTP CH I) is the rate-limiting enzyme in the biosynthesis of the cofactor for $\mathrm{TH}$, aromatic amino acid decarboxylase (AADC) converts L -DOPA to dopamine, and a vesicular monoamine transporter (VMAT-2) transports dopamine into synaptic vesicles, thereby supporting regulated, vesicular release of dopamine and relieving feedback inhibition of TH by dopamine. Helper virus-free herpes simplex virus type 1 vectors that coexpress the three dopamine biosynthetic enzymes (TH, GTP CH I, and AADC; 3-gene-vector) or these three dopamine biosynthetic enzymes and the vesicular monoamine transporter (TH, GTP CH I, AADC, and VMAT-2; 4-gene-vector) were compared. Both vectors supported production of dopamine in cultured fibroblasts. These vectors were microinjected into the striatum of 6-hydroxydopamine-lesioned rats. These vectors carry a modified neurofilament gene promoter, and $\gamma$-aminobutyric acid (GABA)-ergic neuronspecific gene expression was maintained for 14 months after gene transfer. The 4-gene-vector supported higher levels of correction of apomorphine-induced rotational behavior than did the 3gene-vector, and this correction was maintained for 6 months. Proximal to the injection sites, the 4gene-vector, but not the 3-gene-vector, supported extracellular levels of dopamine and dihydroxyphenylacetic acid (DOPAC) that were similar to those observed in normal rats, and only the 4-gene-vector supported significant $\mathrm{K}^{+}$-dependent release of dopamine.
\end{abstract}

\title{
OVERVIEW SUMMARY
}

Address reprint requests to: Dr. Alfred I. Geller, Research Building 3, West Roxbury VA Hospital/Harvard Medical School, 1400 VFW Parkway, West Roxbury, MA 02132 E-mail: alfred_geller@hms.harvard.edu. 
Gene therapy treatments may benefit the management of Parkinson's disease (PD). In the present study, we used a helper virus-free herpes simplex virus type 1 (HSV-1) vector system and a modified neurofilament heavy gene promoter that supports long-term expression in forebrain neurons. We coexpressed tyrosine hydroxylase, GTP cyclohydrolase I, aromatic amino acid decarboxylase, and vesicular monoamine transporter 2 in striatal cells in the 6-hydroxydopamine rat model of PD. Recombinant gene expression was maintained for 14 months in $\gamma$-aminobutyric acid (GABA)-ergic striatal neurons. Long-term behavioral (6 months) and biochemical (3 months) correction was observed with high $\mathrm{K}^{+}$-dependent release of significant levels of dopamine. These results suggest that HSV-1 vectors that coexpress multiple dopamine biosynthetic and transporter genes have promise for developing gene therapy treatments for PD.

\section{INTRODUCTION}

$\mathrm{P}_{\text {ARKINSON'S disease }}(\mathrm{PD})$ is a neurodegenerative disorder largely due to the selective loss of dopaminergic neurons in the substantia nigra pars compacta (SNc) (Yahr and Bergmann, 1987). The reduced levels of striatal dopamine cause resting tremor, rigidity, and severe motor function impairment. The primary treatment for PD is oral administration of ${ }_{L}-3,4-$ dihydroxyphenylalanine (L-DOPA), which restores a varying degree of motor function. The exogenous L-DOPA is converted to dopamine by endogenous aromatic amino acid decarboxylase (AADC), present in surviving dopaminergic neurons (Tashiro et al., 1989). Although initially effective, L-DOPA therapy loses efficacy over time (Yahr and Bergmann, 1987).

A number of alternative, and potentially complementary, therapeutic approaches are under development. Neuroprotection strategies may be useful in the early stages of PD, when significant numbers of nigrostriatal neurons remain. Glial cell-derived neurotrophic factor (GDNF) and brain cell-derived neurotrophic factor (BDNF) can protect nigrostriatal neurons from specific neurotoxins in rodent and monkey models of PD (Hyman et al., 1991; Lin et al., 1993; Yoshimoto et al., 1995; Choi-Lundberg et al., 1997; Bjorklund et al., 2000; Kirik et al., 2000; Kordower et al., 2000). In contrast, production of dopamine in the striatum may be useful during the later stages of PD, after oral L-DOPA therapy loses efficacy. Cell transplantation was the initial approach (Yurek and Sladek, 1990), and transplantation of cells that produce catecholamines can correct animal models of PD (Gage, 1998), but results from human trials have been variable (Lindvall et al., 1990; Barker and Dunnett, 1999; Piccini et al., 1999; Freed et al., 2001). An alternative strategy is to produce dopamine in striatal cells by direct gene transfer of dopamine biosynthetic and transporter genes (Freese et al., 1990; During et al., 1994).

A number of studies together suggest that coexpression of at least four genes will be required for the efficient production and regulated, vesicular release of dopamine from striatal neurons. Tyrosine hydroxylase (TH) converts tyrosine to L-DOPA, and GTP cyclohydrolase I (GTP CH I) is the rate-limiting enzyme in the biosynthesis of the cofactor for $\mathrm{TH}$, tetrahydrobiopterin $\left(\mathrm{BH}_{4}\right)$ (Fitzpatrick, 1999). Coexpression of TH and GTP CH I in fibroblasts supports efficient

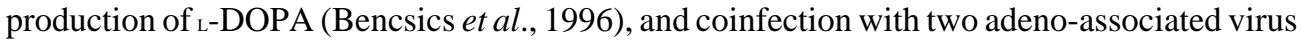
(AAV) vectors that express TH or GTP CH I supports production of ${ }_{\mathrm{L}}$ DOPA (Mandel et al., 1998; Kirik et al., 2002). AADC is sufficient to convert L-DOPA to dopamine, as shown with fibroblasts that coexpress TH and AADC (Kang et al., 1993, 2001; Wachtel et al., 1997). A lentiviral vector that co-expresses TH, GTP CH I, and AADC can correct a rat model of PD, but supports only low levels of striatal dopamine or dihydroxyphenyl acetic acid (DOPAC) (Azzouz et al., 2002), and coinjection of three AAV vectors that express these three genes can correct rat and monkey models of PD (Shen et al., 2000; Muramatsu et al., 2002). A vesicular monoamine transporter (VMAT-2) transports dopamine into synaptic vesicles (Liu et al., 
1992), and fibroblasts that coexpress AADC and VMAT-2 support improved storage and sustained release of dopamine (Lee et al., 1999). In neurons, sequestering dopamine into synaptic vesicles enables the regulated, vesicular release of dopamine (Johnson, 1988; Liu et al., 1992) and relieves feedback inhibition of TH by dopamine (Fitzpatrick, 1999).

The central hypothesis of this study is that coexpression of four dopamine biosynthetic and transporter genes (TH, GTP CH I, AADC, and VMAT-2) in striatal neurons can support the efficient production and regulated, vesicular release of dopamine. Efficient coexpression of these four genes may require a single, large vector that contains these genes, and herpes simplex virus (HSV-1) vectors or adenoviral vectors have large capacities. In one of the first studies to correct the rat model of PD with a viral vector, we used a helper virus-containing HSV-1 vector that expressed TH (During et al., 1994). Limitations of this study included the side effects of this vector system, limited long-term expression, and expression only of TH (Isacson, 1995; Mandel et al., 1998). We subsequently developed a helper virus-free HSV-1 vector system that supports gene transfer with minimal side effects (Fraefel et al., 1996), and a modified neurofilament gene promoter that supports long-term expression in forebrain neurons (Zhang et al., 2000). Using this improved system, we reported (Sun et al., 2003) coexpression of TH and AADC for 8 months, and correction of the rat model of PD for 5 weeks.

This study compares correction of the rat model of PD by HSV-1 vectors that coexpress either the three dopamine biosynthetic enzymes (TH, GTP CH I, and AADC; 3-gene-vector) or these three dopamine biosynthetic enzymes and a vesicular monoamine transporter (TH, GTP CH I, AADC, and VMAT-2; 4-gene-vector). The 4-gene-vector supported higher levels of correction of apomorphine-induced rotational behavior than the 3-gene-vector, and only the 4-gene-vector supported high $\mathrm{K}^{+}$-dependent release of high levels of dopamine.

\section{MATERIALS AND METHODS}

\section{HSV-1 vector constructions}

pBR-8cutter-linker-II, pBR-73linker-Cm ${ }^{\mathrm{r}}(-)$, pBR-73linker-Kn ${ }^{\mathrm{r}}$-PmeI, and pHSVpUClinker-II (Wang et al., 2001) have been described. p533 (pflag-th), p747 (pHA-th/ires/aadc), p903 (pflag-th/ires/gtpch), and pHSVPrPUCgtpch were generous gifts from K. O'Malley (Moffat et al., 1997). These plasmids contain tTH, a deletion of the human TH type II cDNA that removes the protein kinase A (PKA) phosphorylation site, a human GTP CH I cDNA, a human AADC cDNA, and an internal ribosome entry site (IRES). phavmat, a hemagglutinin (HA)-tagged rat VMAT-2 cDNA, was a generous gift from R. Edwards (Liu et al., 1992). Constructions were performed by standard recombinant DNA procedures (Maniatis et al., 1989).

pINS-TH-NFHlac (lacZ-vector)—This vector has been described (Zhang et al., 2000). The modified neurofilament gene promoter in these vectors was isolated in two steps: addition of $5^{\prime}$ upstream sequences from the rat TH promoter to the mouse neurofilament heavy (NFH) gene promoter enhances long-term expression, and addition of a chicken $\beta$-globin insulator (INS) further improves long-term expression (INS-TH-NFH promoter).

pINS-TH-NFHha-th/ires/aadc (2-gene-vector)-This vector has been described (Sun $e t$ al., 2003).

pINS-TH-NFHflag-th/ires/aadc VINS-TH-NFHgtpch (3-gene-vector)-pBR-8cutterlinker-II was digested with PacI and NotI, the two fragments were religated to eliminate the flanking $A s c I$ sites, and this plasmid was designated pBR-8cutter-linker-III. Two oligonucleotides (5'-CCGTTTAAACGGCGCGCCATT-TAAATCACCGGTGC-3'and 5'TCGAGCACCGGTGATT-TAAATGGCGCGCCGTTTAAACGGCCGG-3') were inserted 
between the FseI and XhoI sites of pBR-8cutter-linker-III to yield pBR-8cutter-linker-IV. pBR-8cutter-linker-IV was digested with PacI and NotI, and the linker was inserted into pHSVpUC-linker-II that had been digested with PacI and NotI to yield pHSVpUC-8cutterlinker-III. An $\sim 8$-kb fragment containing the INS-TH-NFH promoter was isolated from pINSTH-NHFlac by a SalI complete, HindIII partial digestion; a GTP CH I cDNA (840 bp) was

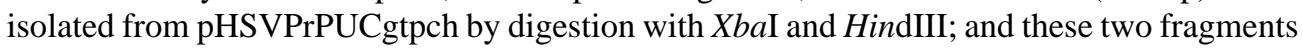
were inserted into pBR-73linker- $\mathrm{Cm}^{\mathrm{r}}(-)$ that had been digested with $\mathrm{XbaI}$ and $\mathrm{XhoI}$ to yield pBR-INS-TH-NFHgtpch. pBR-INS-TH-NFHgtpch was digested with FseI and the 11.1-kb fragment containing the transcription unit was inserted into pHSVpUC-8cutter-linker-III that had been digested with $F s e$ I and treated with calf intestinal phosphatase (CIP) to yield pINSTH-NFHgtpch. The INS-TH-NFH promoter fragment was isolated as described above $(\sim 8-\mathrm{kb}$ SalI and HindIII fragment); a 436-bp fragment containing the 5' part of the FLAG-TH cDNA was isolated from p533 by digestion with FseI and HindIII; a 2.9-kb fragment containing the 3' part of the TH cDNA, an IRES, and a human AADC cDNA was isolated from p747 by FseI complete, EcoRI partial digestion; and these three fragments were inserted into pBR-73linker-Knn ${ }^{\mathrm{r}}$-PmeI that had been digested with SalI and EcoRI to yield pBR-INS-THNFHflag-th/ires/aadc-PmeI. Two oligonucleotides (5' -AATTGGGCGCGCCGTTTAAACGGCGCGCCA-3' and 5' -GGCCTGGCGCGCCGTTTAAACGGCGCGCCC-3' ) were inserted into pBR322 that had been digested with $E c o$ RI and EagI to yield pBR-AscI-linker (contains a linker with a PmeI site flanked by two AscI sites). pBR-INS-TH-NFHflag-th/ires/aadc-PmeI was digested with PmeI and the transcription unit (14.2-kb fragment) was inserted into $\mathrm{pBR}$-AscI-linker that had been digested with PmeI and treated with CIP to yield pBR-INS-TH-NFH-flag-th/ires/aadc-AscI. pBR-INSTH-NFHflag-th/ires/aadc-AscI was digested with $A s c I$ and the fragment containing the transcription unit was inserted into pINS-TH-NFHgtpch that had been digested with AscI and treated with CIP to yield pINS-TH-NFHflag-th/ires/aadclINS-TH-NFHgtpch (3-gene-vector).

\section{pINS-TH-NFHflag-th/ires/aadclINS-TH-NFHha-vmat/ires/ gtpch (4-gene-vector)}

-A 1.6-kb fragment that contains a HA-VMAT-2 cDNA was isolated by polymerase chain reaction (PCR) (template, phavmat; 5' primer, $5^{\prime}$ -

GCGAAGCTTAGTCACAGGCGAGCCAGAGCAGAGC-3' [nucleotides 46 to 70; Liu et al., 1992]; 3' primer, 5' -GGGTCGGCCGTGGGC-GACGTTAGAGGGTCTCAGTC-3' [complementary to nucleotides 1614 to 1637]). This PCR fragment was digested with EagI and HindIII; p903 was digested with NotI and $X b a \mathrm{I}$, and the 1.8-kb fragment was isolated (contains ires/gtpch); and these two fragments were inserted into p903 that had been digested with HindIII and $X b a \mathrm{I}$ (3.5-kb vector backbone fragment) to yield phavmat/ires/gtpch. The INS-TH-NFH promoter fragment was isolated as described above ( 8-kb SalI and HindIII fragment); phavmat/ires/gtpch was digested with EagI and HindIII, and the 1.6-kb fragment was isolated (contains HA-VMAT-2); phavmat/ires/gtpch was digested with EagI and XbaI, and the 1.8-kb fragment was isolated (contains ires/gt-pch); and these three fragments were inserted into pBR-73linker-Cm ${ }^{\mathrm{r}}(-)$ that had been digested with $\mathrm{XbaI}$ and $\mathrm{XhoI}$ to yield pBRINS-TH-NFHha-vmat/ires/gtpch. pBR-INS-TH-NFHha-vmat/ires/gtpch was digested with FseI and the fragment containing the transcription unit was inserted into pHSVpUC-8cutterlinker-III that had been digested with $F s e$ I and treated with CIP to yield pINS-TH-NFHhavmat/ires/gtpch. pBR-INS-TH-NFHflag-th/ires/aadc was digested with AscI and the fragment containing the transcription unit was inserted into pINS-TH-NFHha-vmat/ires/gtpch that had been digested with AscI and treated with CIP to yield pINS-TH-NFHflag-th/ires/aadclINSTH-NFHha-vmat/ires/gtpch (4-gene-vector).

\section{Cell culture}

2-2 cells (Smith et al., 1992) and baby hamster kidney (BHK) cells were maintained in Dulbecco's modified minimal essential medium (DMEM) supplemented with $10 \%$ fetal bovine 
serum (FBS), penicillin-streptomycin, and $4 \mathrm{~m} M$ glutamine (media and chemicals from Invitrogen, Carlsbad, CA) in humidified incubators containing $5 \% \mathrm{CO}_{2}$ at $37^{\circ} \mathrm{C}$. $\mathrm{G} 418(0.5$ $\mathrm{mg} / \mathrm{ml}$; RPI, Mount Prospect, IL) was present during the growth of 2-2 cells, but was removed before plating the cells for HSV-1 vector packaging.

\section{Vector packaging}

Vectors were packaged into HSV-1 particles, using the helper virus-free packaging system (Fraefel et al., 1996) as modified to improve the titers (Sun et al., 1999). Vector stocks were purified and concentrated as described (Lim et al., 1996).

\section{Immunocytochemistry and vector titering}

For titering, $5 \times 10^{5}$ BHK cells in $0.5 \mathrm{ml}$ were plated in a 24-well plate and 1 day later infected with specific amounts of a specific vector, or mock infected. For immunocytochemistry, $3 \times$ $10^{5} \mathrm{BHK}$ cells in $0.5 \mathrm{ml}$ were plated into each chamber of poly-D-lysine-coated eight-chamber slides (BIOCOAT; BD Biosciences Discovery Labware, Bedford, MA) and $2 \mathrm{hr}$ later were infected with a specific vector, or mock infected. One day after infection, the cells were fixed with $4 \%(\mathrm{w} / \mathrm{v})$ paraformaldehyde for $10 \mathrm{~min}(\mathrm{~min})$, washed three times with phosphatebuffered saline (PBS), and then incubated overnight at $4^{\circ} \mathrm{C}$ with the appropriate primary antibody; primary antibodies were mouse monoclonal anti-FLAG (1:1000 dilution; Sigma, St. Louis, MO), rabbit anti-GTP CH I (1:500 dilution; Pluss et al., 1996), rabbit anti-human AADC (human specific, 1:500 dilution; gift from J. Haycock, Department of Biochemistry, Louisiana State University Medical Center, New Orleans, LA), and rabbit anti-HA (1:500 dilution; Covance Research Products [formerly BAbCO], Richmond, CA). Cells were washed three times with PBS and then incubated with either alkaline phosphatase (AP)-conjugated goat antimouse IgG or AP-conjugated goat anti-rabbit IgG (1:500 dilutions; Vector Laboratories, Burlingame, CA) for $2 \mathrm{hr}$ at room temperature. Antibody staining was visualized with 5bromo-4-chloro-3-indolylphosphate toluidinium-nitroblue tetrazolium substrate (BCIP-NBT; Sigma). Escherichia coli $\beta$-galactosidase ( $\beta$-Gal) was detected by 5-bromo-4-chloro-3-indoyl$\beta$-- -galac-topyranoside (X-Gal; Sigma) staining (Song et al., 1997). Vectors were titered by counting the numbers of positive cells, and the titers of the vector stocks used in this study are shown in Table 1. No HSV-1 ( $<10$ plaque-forming units/ml) was detected in any of the vector stocks.

\section{Catecholamine production in cultured cells}

BHK cells $\left(7 \times 10^{5}\right)$ in $0.5 \mathrm{ml}$ were infected with a specific vector (multiplicity of infection, 0.1 ), or mock infected. One day later, the cells were incubated in neurobasal medium containing $1 \% \mathrm{~N}-2$ supplement (Invitrogen) and $25 \mu M_{\mathrm{L}}$-gluta-mine at $37^{\circ} \mathrm{C}$ for $6 \mathrm{hr}$, and $0.5 \mathrm{mM} \mathrm{BH}_{4}$ (cofactor for TH; Sigma) was added to specific cultures (Geller et al., 1995). The cells were washed twice with a physiological buffer ( $135 \mathrm{~m} M \mathrm{NaCl}, 3 \mathrm{~m} M \mathrm{KCl}, 1 \mathrm{~m} M \mathrm{MgCl}_{2}, 1.2 \mathrm{~m} M$ $\mathrm{NaPO}_{4}$ [pH 7.4], $10 \mathrm{~m} M$ glucose), and then lysed in $0.5 \mathrm{ml}$ of ice-cold $0.1 M \mathrm{HClO}_{4}, 1 \%$ $\mathrm{Na}_{2} \mathrm{~S}_{2} \mathrm{O}_{5}$ (Geller et al., 1995). Cell lysates were sonicated for $2 \mathrm{~min}$, clarified by centrifugation at top speed in a micro-centrifuge at $4^{\circ} \mathrm{C}$ for $5 \mathrm{~min}$, and assayed by quantitative highperformance liquid chromatography (HPLC) with electrochemical detection (Holmes et al., 1994; Yadid et al., 2000). The levels of L-DOPA, dopamine, and DOPAC were determined in each sample.

\section{6-Hydroxydopamine lesions}

All animal procedures were approved by the West Roxbury VA Hospital (West Roxbury, MA) Institutional Animal Care and Use Committee. Male Sprague-Dawley rats (225-250 g) were obtained from Charles River (Wilmington, MA). Rats received food and water ad libitum. The cages were kept in a temperature- and humidity-controlled room with a 12-hr light-dark cycle. 
To establish no preexisting rotational bias, 2-3 days after arrival from the vendor, the rats were tested for apomorphine-induced rotational behavior ( $1 \mathrm{mg} / \mathrm{kg}$, intraperitoneal; Sigma), using a computer-controlled rotameter (Omnitech Electronics, Columbus, $\mathrm{OH}$ ), and rats that exhibited fewer than two net turns per 5 min were used in this study. Rats were anesthetized with ketamine (60-80 mg/kg) and xylazine (5-10 mg/kg) (Fisher, Fairlawn, NJ), and placed in a stereotaxic frame. 6-Hydroxydopamine (6-OHDA, $2 \mu \mathrm{g} / \mu \mathrm{l}$ in ascorbate-saline; Sigma) was microinjected at each of two sites $(2.5 \mu \mathrm{l} / \mathrm{site})$ in the substantia nigra (anteroposterior [AP], -5.5; mediolateral [ML], 1.9; dorsoventral [DV], -7.1; and AP-5.5, ML 2.3, DV -6.8) (Perese et al., 1989). AP is relative to bregma, ML is relative to the sagittal suture, and DV is relative to the bregma-lambda plane (Paxinos and Watson, 1986). Starting 3 weeks later, the rats were tested for apomorphine-induced rotational behavior (once per week for 3-5 weeks). Clockwise turns (ipsilateral to the lesion) were counted as positive turns, and counterclockwise turns were counted as negative turns. The net apomorphine-induced rotations performed by each rat were calculated as the difference between the clockwise and counterclockwise turns over the 60min period after injection of apomorphine. Rats that exhibited an average of five rotations or more per minute during the 15- to 20-min interval after injection of apomorphine were used for gene transfer. This rotation rate is consistent with a $\geq 90 \%$ reduction in the number of nigrostriatal neurons (Hefti et al., 1980a; Carman et al., 1991).

\section{Gene transfer and rotational testing}

Lesioned rats were randomly assigned to the different gene transfer groups. A specific vector or PBS was injected at each of three sites in the right striatum ( $3 \mu \mathrm{l} / \mathrm{site}$ : AP 0.6, ML 2.0, DV -5.0; AP 0.6, ML 3.2, DV -5.0; and AP 1.8, ML 2.6, DV -5.0) (Paxinos and Watson, 1986). Starting 3 weeks after gene transfer, apomorphine-induced rotational behavior was tested each week for 2 months, and then every other week until the rats were killed.

\section{Immunohistochemistry}

Rats were perfused transcardially with $100 \mathrm{ml}$ of PBS followed by $200 \mathrm{ml}$ of ice-cold $4 \%$ paraformaldehyde in PBS. Brains were dissected out, postfixed in the same solution for $4 \mathrm{hr}$ at $4^{\circ} \mathrm{C}$, and cryoprotected in $30 \%$ sucrose in PBS at $4^{\circ} \mathrm{C}$. Coronal brain sections $(25 \mu \mathrm{m})$ were cut on a freezing microtome, and immunohistochemistry was performed as described (Sun $e t$ al., 2003). Anti-FLAG, anti-human AADC, and anti-HA antibodies were used at the dilutions specified (see Im-munocytochemistry and Vector Titering, above). The other primary antibodies were mouse monoclonal anti-TH antibody (1:200 dilution; Roche Laboratories, Nutley, NJ), mouse monoclonal anti- $\mu$-Gal (1:500 dilution; Sigma), mouse monoclonal antineuron-specific nuclear protein (NeuN, 1:200 dilution; Chemicon International, Temecula, $\mathrm{CA}$ ), and rat anti-glutamic acid decarboxylase (GAD, 1:500 dilution; Chemicon International). Antibodies were visualized with biotinylated secondary antibodies and the avidin-biotinylated peroxidase complex $(\mathrm{ABC})$ reagent or with fluorescein or rhodamine isothiocyanateconjugated secondary antibodies (Vector Laboratories).

\section{Cell counts}

Coronal brain sections $(25 \mu)$ were analyzed from the area in close proximity to the injection sites. For most rats and assays, every fourth section was analyzed, and $\sim 12$ of these sections contained positive cells. Stereology was used to determine the numbers of positive cells in the striatum. With reference to a rat atlas (Paxinos and Watson, 1986) and known landmarks, a contour was drawn around the striatum in each of the 12 sections that contained positive cells. Stereology was performed according to the optical dissector method and with the Stereo Investigator program (MicroBrightField, Williston, VT). Stereological cell counts were performed under $\times 60$ magnification, the counting frame area was $1 \times 10^{4} \mu \mathrm{m}^{2}$, a mean of 772 sites per rat was counted, and the coefficient of error for each rat was $\leq 10 \%$. For 
immunofluorescence costaining assays, 5-8 randomly chosen sections were stained with the appropriate antibodies, at least 200 positive cells were scored for each costaining assay, and all the positive cells in the examined sections were scored.

\section{RNA analysis}

Human GTP CH I RNA was detected by reverse transcription-polymerase chain reaction (RTPCR). The striatum was dissected and immediately frozen in dry ice-ethanol, and total RNA was isolated with an RNeasy lipid tissue midi kit (Qiagen, Valencia, CA). RT-PCR was performed with a Qiagen OneStep RT-PCR kit. One microgram of RNA was transcribed into cDNA; the reverse transcription reaction was performed at $50^{\circ} \mathrm{C}$ for $35 \mathrm{~min}$. Reactions were incubated at $95^{\circ} \mathrm{C}$ for 16 min to activate the HotStarTaq DNA polymerase. The primer used for reverse transcription, which was also used for PCR, was from the human GTP CH I cDNA (5'-GCTACTGGCAGT-ACGATCGGCAACC-3', complementary to nucleotides 925 to 949; Nomura et al., 1995). The other primer used for PCR was also from the human GTP CH I (5'CCATGTGTGAGCAT-CACTTGGTTCC-3', nucleotides 564 to 588). These two primers are specific for the recombinant human GTP CH I gene and do not recognize the endogenous rat GTP CH I gene (NIH NCBI nucleotide-nucleotide BLAST program). The conditions for the PCR were 39 cycles of $95^{\circ} \mathrm{C}$ for $1 \mathrm{~min}, 55^{\circ} \mathrm{C}$ for $1 \mathrm{~min}$, and $72^{\circ} \mathrm{C}$ for $1 \mathrm{~min}$, with a final extension time of $10 \mathrm{~min}$ at $72^{\circ} \mathrm{C}$. The PCR products were separated on a $1.2 \%$ agarose gel.

\section{Microdialysis}

In selected rats, microdialysis was performed at an average of 3 months after gene transfer on awake, freely moving rats. A guide cannula was implanted (AP 0.6, ML 2.6). The guide cannula was located between the three injection sites used for gene transfer (coordinates for the three injection sites are presented above). The dialysis probes had a molecular mass cutoff of $20 \mathrm{kDa}$ (CMA12; CMA Microdialysis, North Chelms-ford, MA). Microdialysis was performed 2-3 days after insertion of the guide cannula. To insert the dialysis probe, the rat was briefly anesthetized with isoflurane for approximately $5 \mathrm{~min}$. The probe was inserted through the cannula, and the exposed 4-mm membrane spanned the dorsoventral coordinates of the striatum. After equilibration for $2 \mathrm{hr}$, dialysates were collected in artificial cerebral spinal fluid (CSF) that contained low $\mathrm{K}^{+}\left(147 \mathrm{~m} M \mathrm{NaCl}, 2.7 \mathrm{~m} M \mathrm{KCl}, 1.2 \mathrm{~m} M \mathrm{CaCl}_{2}, 0.85 \mathrm{mM} \mathrm{MgCl}\right.$ )

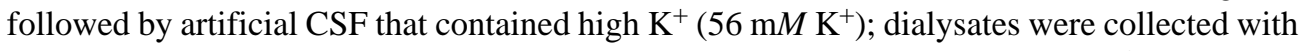
a micropump (CMA/100, 1.5- $\mu 1 / \mathrm{min}$ flow rate) (During et al., 1994). The low $\mathrm{K}^{+}$condition dialysate was collected for $1 \mathrm{hr}$ and the high $\mathrm{K}^{+}$condition dialysate was collected for $15 \mathrm{~min}$. The dialysate flow rate was the same for both conditions, the data are reported as picograms $\left(\times 10^{3}\right)$ per milliliter, and reporting these measurements as concentrations enables comparisons between the low- $\mathrm{K}^{+}$and high- $\mathrm{K}^{+}$conditions. Catecholamines were assayed by HPLC with electrochemical detection (Holmes et al., 1994; Ya-did et al., 2000). The levels of L-DOPA, dopamine, and DOPAC were determined in each sample.

\section{Statistical analyses}

Neurochemical and behavioral data were analyzed for statistically significant differences by between-group analysis of variance (ANOVA) followed by pairwise multiple comparisons (Tukey test), when appropriate (SigmaStat; SPSS, Chicago, IL).

\section{RESULTS}

\section{HSV-1 vectors that coexpress multiple dopamine biosynthetic and transporter genes}

The central hypothesis of this study is that coexpression of three dopamine biosynthetic enzymes (TH, GTP CH I, and AADC) and a vesicular monoamine transporter in striatal neurons can support the efficient production and regulated, vesicular release of dopamine (Fig.

Hum Gene Ther. Author manuscript; available in PMC 2008 November 10. 
1A). To examine the importance of sequestering dopamine into synaptic vesicles, HSV-1 vectors were constructed that coexpress the three dopamine biosynthetic enzymes (TH, GTP $\mathrm{CH}$ I, and AADC; 3-gene-vector), or the three dopamine biosynthetic enzymes and a vesicular monoamine transporter (TH, GTP CH I, AADC, and VMAT-2; 4-gene-vector; Fig. 1B). Control vectors expressed both TH and AADC (2-gene-vector; Sun et al., 2003) or E. coli $\beta$ Gal (lacZ-vector; Zhang et al., 2000). All of these vectors contain a modified neurofilament heavy gene promoter (INS-TH-NFH promoter) that supports long-term expression in forebrain neurons (Zhang et al., 2000). A previously published time course showed that the number of expressing cells in the striatum is relatively stable between 2 weeks and 6 months after gene transfer (time points at 2 weeks, 1 month, and 2, 4, and 6 months; Zhang et al., 2000).

Expression was observed for 6 months (Zhang et al., 2000) or 8 months (Sun et al., 2003), the longest time points examined in these studies. The 3-gene-vector and the 4-gene-vector contain two transcription units; the first transcription unit contains TH with a FLAG tag (FLAG-TH), an IRES, and AADC (flag-th/ires/aadc); and the second transcription unit contains either GTP CH I (3-gene-vector) or VMAT-2 with an HA tag (HA-VMAT), an IRES, and GTP CH I (havmat/ ires/gtpch, 4-gene-vector; Fig. 1B). The 2-gene-vector contains a single transcription unit that includes TH with an HA tag (HA-TH), an IRES, and AADC (ha-th/ires/aadc) (Moffat et al., 1997;Sun et al., 2003).

\section{Expression of dopamine biosynthetic and transporter proteins in cultured cells}

Vectors were packaged using a helper virus-free HSV-1 packaging system, and vector stocks were purified (Fraefel et al., 1996; Sun et al., 2003). Vector stocks were titered 1 day after infection of BHK fibroblasts, as the best available assay. Expression from the INS-TH-NFH promoter in these fibroblasts represents ectopic expression that declines rapidly; however, the lacZ-vector supports higher titers on BHK cells than on neural cells, such as PC12 cells, possibly because only the BHK cells form a monolayer (Zhang et al., 2000; Yang et al., 2001). Nonetheless, the titers obtained on BHK cells are useful; with the lacZ-vector, the titer of vector genomes, as determined in a PCR assay, is 4.1-fold higher than the biological titer, as determined by X-Gal staining of BHK cells (Yang et al., 2001). To titer the present vectors, recombinant gene products were detected with antibodies against FLAG (detects FLAG-TH), GTP CH I, human AADC, or HA (detects HA-VMAT-2); or $\beta$-Gal was detected by X-Gal staining. One day after infection with the 4-gene-vector, we detected the four predicted immunoreactivities: FLAG-IR, GTP CH I-IR, human AADC-IR, and HA-IR (Fig. 2A-D). In mock-infected cells, none of these four IRs was detected (Fig. 2E-H). The human AADC antibody is human specific and does not recognize rat AADC. The GTP CH I antibody is panspecific and also recognizes rat GTP CH I (Pluss et al., 1996); however, GTP CH I is expressed in monoamine-producing cells and is not expressed in fibroblasts (Hirayama et al., 1993; Hirayama and Kapatos, 1998). Also, 1 day after infection with the 3-gene-vector, we detected the three predicted IRs, FLAG-IR, GTP CH I-IR, and human AADC-IR (data not shown). Both the 3-gene-vector and the 4-gene-vector supported similar titers of FLAG-TH, GTP CH I, and AADC (Table 1). Using the 4-gene-vector, the titer of VMAT-2 was 10-fold lower than the titers of the other three genes, possibly because these fibroblasts lack a synaptic vesicle compartment. The HA-IR staining is similar to that previously reported in fibroblasts stably transfected with VMAT-2 (Lee et al., 1999). The 3-gene-vector and the 4-gene-vector had titers similar to those of the control vectors, which express only one or two genes.

Colocalization of these gene products to the same striatal neurons is described below.

\section{Production of catecholamines in cultured cells}

BHK cells were infected with specific vectors, 1 day later the cultures were incubated for $6 \mathrm{hr}$ in defined medium with or without the cofactor for $\mathrm{TH}\left(\mathrm{BH}_{4}\right)$, cell lysates were prepared, and catecholamine levels were quantified by HPLC with electrochemical detection. The lacZvector did not support the production of detectable levels of any catecholamines compared 
with mock-infected cultures (Table 2). The 2-gene-vector co-expresses TH and AADC, but because this vector does not express GTP CH I, we expected that addition of exogenous cofactor for TH would be required to obtain significant levels of TH activity. The results showed that in the absence of the cofactor for TH, the 2-gene-vector did not support the production of any catecholamines (Table 2). But with the addition of exogenous cofactor $\left(\mathrm{BH}_{4}\right)$, the 2-gene-vector supported production of dopamine and DOPAC. Both the 3-genevector and the 4-gene-vector coexpress three dopamine biosynthetic enzymes: TH, GTP CH $\mathrm{I}$, and AADC; and we expected that these vectors would support significant levels of TH activity in the absence of exogenous cofactor. The results showed that both the 3-gene-vector and the 4-gene-vector supported the production of dopamine and DOPAC, without addition of exogenous cofactor (Table 2). The levels of L-DOPA supported by the 2-gene-vector (with cofactor), or of the 3-gene-vector or the 4-gene-vector (without cofactor), were not significantly different from the corresponding control conditions (mock infected with or without cofactor, respectively; $p>0.05$, ANOVA), consistent with efficient conversion of ${ }_{\mathrm{L}}$-DOPA to dopamine. The levels of dopamine supported by the 2-gene-vector (with cofactor) were not significantly different from the levels supported by either the 3-gene-vector or the 4-gene-vector (without cofactor; $p>0.05$ ); this comparison should be interpreted cautiously because the 2 -gene-vector likely supported significant levels of TH activity only during the 6-hr period when exogenous cofactor was present, but both the 3-gene-vector and the 4-gene-vector likely initiated production of catecholamines shortly after gene transfer, resulting in a longer period ( $\sim 1$ day) of catecholamine production. The 3-gene-vector supported $\sim 3$-fold higher levels of dopamine and DOPAC compared with the levels supported by the 4-gene-vector $(p<0.02)$. It is possible that the 3-gene-vector produced higher levels of GTP CH I than did the 4-gene-vector; in the 4-gene-vector, the upstream VMAT-2 gene might reduce expression of GTP CH I (ha-vmat/ ires/gtpch cassette); however, the immunocytochemical staining for GTP CH I-IR was similar when using these two vectors. Alternatively, fibroblasts stably transfected with VMAT-2 secrete higher levels of dopamine into the medium than do the corresponding control cells (Lee et al., 1999), suggesting that the 4-gene-vector may support higher extracellular levels of dopamine than the 3-gene-vector. In the present experiment, we did not examine the levels of catecholamines in the medium. The purpose of this experiment was to establish that both the 3 -gene-vector and the 4-gene-vector support the production of dopamine without addition of cofactor, as shown in Table 2.

\section{Expression of dopamine biosynthetic and transporter proteins in striatal cells}

Stocks of either the 3-gene-vector or the 4-gene-vector were microinjected into rat striatum. Gene transfer was performed via the three injection sites from previous studies that corrected the rat model of PD (During et al., 1994; Sun et al., 2003). In these initial experiments, rats were killed 4 days after gene transfer. Recombinant gene products were detected by immunohistochemistry, using antibodies against FLAG, human AADC (human-specific), or $\mathrm{HA}$, and antibodies were visualized by the $\mathrm{ABC}$ procedure. Detection of recombinant human GTP CH I RNA, and of GTP CH I-IR-positive striatal cells, are described in a later section. A rat that received the 4-gene-vector contained FLAG-IR, human AADC-IR, or HA-IR-positive striatal cells (Fig. 3A-C). The positive cells were located within $\sim 1.2 \mathrm{~mm}$ in the anteroposterior direction. In the con-tralateral, uninjected striatum, no cells positive for FLAG-IR (Fig. 3D), or for human AADC-IR or HA-IR (data not shown), were detected. Small numbers of positive cells were observed near the needle tracks in the neocortex (data not shown). These results show that the vast majority of transfected cells were located in the striatum, within $\sim 3 \mathrm{~mm}$ along the rostrocaudal axis in close proximity to the injection sites, and distant sites contained few transfected cells (because of retrograde transport of the vector). Similarly, a rat that received the 3-gene-vector contained FLAG-IR- or human AADC-IR-positive striatal cells (data not shown). Also, these results are consistent with earlier studies that delivered HSV-1 
vectors into the striatum (During et al., 1994; Sun et al., 1999, 2003; Zhang et al., 2000). Thus, the present analyses focused on the transfected striatal cells near the injection sites.

Coexpression of specific combinations of two recombinant proteins in the same cells was established by immunofluorescence colocalization. FLAG-IR and human AADC-IR were detected in the same cells (Fig. 3E-G). Also, human AADC-IR and HA-IR were detected in the same cells (Fig. $3 \mathrm{H}-\mathrm{J}$ ). Cell counts to determine the percentages of costained cells are presented with the same assays of long-term expression in the next section. Specificity of the immunofluorescence assays was established by examining the contralateral, uninjected striatum; no cells positive for FLAG-IR or human AADC-IR (Fig. 3K-M), or HA-IR (data not shown), were detected in the con-tralateral striatum.

The types of transfected cells were identified by immunofluorescence colocalization of specific recombinant proteins and specific cell markers. Neurons were identified with an antibody against NeuN (Mullen et al., 1992), and $\gamma$-aminobutyric acid (GABA)-ergic medium spiny neurons, the principal type of striatal neuron, were identified with an antibody against GAD. Human AADC-IR-positive neurons were detected (Fig. 3N-P), and FLAG-IR-positive GABA-ergic neurons were also observed (Fig. 3Q-S). Cell counts to determine the percentages of costained cells are presented with the same assays of long-term expression in the next section.

\section{Long-term, GABA-ergic neuron-specific expression of dopamine biosynthetic and transporter proteins in the striatum of 6-OHDA-lesioned rats}

The 4-gene-vector was microinjected into the partially denervated striatum of 6-OHDAlesioned rats, the rats were killed 5, 8, or 14 months after gene transfer, and recombinant gene expression was assayed. FLAG-IR-positive striatal cells were detected in the striatum of each of three rats that were killed 5, 8, or 14 months after gene transfer, respectively (Fig. 4A-C). Human AADC-IR-positive striatal cells were detected in rats killed either 5 or 14 months after gene transfer (Fig. 4E and F), and this assay was not performed on the rat killed at 8 months. We observed only punctate staining for AADC that was usually restricted to the cell bodies and in a few cells extended into the proximal processes. AADC is the second gene in the flagth/ires/aadc cassette, and it is often observed that the gene after the IRES in such cassettes is expressed at a lower level than the first gene. Also, the human AADC-specific antibody may have a lower sensitivity than the antibodies that recognize the FLAG or HA tag. The punctate staining is a positive signal and was not observed in the contralateral, uninjected striatum. HAIR-positive striatal cells were observed in each of these three rats (Fig. 4H-J). No cells positive for FLAG-IR, human AADC-IR, or HA-IR were observed in the contralateral striatum from each of these three rats (5 or 8 months, data not shown; 14 months; Fig. 4D, G, and K). In addition, rats that received the 3 -gene-vector, and were killed 4 months after gene transfer, contained FLAG-IR- or human AADC-IR-positive striatal cells (data not shown). Stereological cell counts showed that three rats killed 5-6 months after receiving the 4-gene-vector contained an average of 11,400 \pm 2850 FLAG-IR-positive striatal cells (mean \pm SEM).

Next, we examined coexpression of specific combinations of two recombinant proteins in the same cells. A rat that received the 4-gene-vector and was killed 14 months after gene transfer contained FLAG-IR and human AADC-IR in the same striatal cells (Fig. 5A-C), and similar results were observed in rats that were killed 4,6 , or 8 months after receiving the 3 -gene-vector (data not shown). Cell counts showed that 98 or $94 \%$ of the positive cells contained both FLAGIR and human AADC-IR in rats killed either 4 days or 14 months after receiving the 4-genevector, respectively (Table 3). In both the 3-gene-vector and the 4-gene-vector, the FLAG-TH gene is located before an IRES, and the AADC gene is located after an IRES (flag-th/ ires/aadc cassette). Thus, two genes located either before or after an IRES are coexpressed in the preponderance of transfected cells. A rat that received the 4-gene-vector and was killed 14 
months after gene transfer also contained human AADC-IR and HA-IR in the same striatal cells (Fig. 5D-F). Cell counts showed that 94 or $99 \%$ of the positive cells contained both human AADC-IR and HA-IR in rats killed either 4 days or 14 months after gene transfer, respectively (Table 3). In the 4-gene-vector, one transcription unit contains the AADC gene, and the other transcription unit contains the HA-VMAT-2 gene. Thus, these results demonstrate that the two transcription units are co-expressed in the vast majority of the transfected cells.

Most of the immunostaining was detected in cell bodies, and some staining was observed in proximal processes (Figs. 3-5). FLAG-IR and human AADC-IR were usually observed in cell bodies, and occasionally in proximal processes. HA-IR was observed in both cell bodies and proximal processes. These three different assays may have different sensitivities that could contribute to the observed intracellular locations of the IRs, and HA-VMAT-2 may be targeted to a synaptic vesicle compartment.

We identified the types of striatal cells that support recombinant gene expression. A rat that received the 4-gene-vector and was killed 14 months after gene transfer contained human AADC-IR-positive neurons (Fig. 5G-I), and similar results were observed in a rat that was killed 4 months after receiving the 3-gene-vector (data not shown). Cell counts showed that 95 or $96 \%$ of the positive cells were neurons in rats killed either 4 days or 14 months after receiving the 4-gene-vector, respectively (Table 3). A rat that received the 4-gene-vector and was killed 6 months after gene transfer contained FLAG-IR-positive GABA-ergic neurons (Fig. 5J-L). Cell counts showed that 97 or $86 \%$ of the positive cells were GABA-ergic neurons in rats killed either 4 days or 6 months after receiving the 4-gene-vector, respectively (Table 3 ). A rat killed 7 weeks after receiving the lacZ-vector contained $\beta$-Gal-IR-positive neurons (Fig. 6), and we did not observe any cells that contained FLAG-IR, human AADC-IR, or HAIR (data not shown).

Any side effects caused by this vector system were below the sensitivities of the assays used in this and previous studies. All the rats in this study gained weight and exhibited normal gross motor behaviors except when treated with apomorphine. The rats survived until they were killed and, on histological analysis, no brain tumors were observed. The NeuN-IR and GADIR assays showed apparently normal numbers and patterns of neurons and GABA-ergic neurons, respectively, near the injection sites, although stereological cell counts were not performed. There was minimal cell infiltration near the needle tracks in rats killed 4 days after gene transfer, and virtually no cell infiltration was observed in rats killed between 1 and 14 months after gene transfer. Other studies have shown that microinjection of helper virus-free HSV-1 vectors elicits a minimal immune response (Fraefel et al., 1996; Zhang and Geller, 2002; Bowers et al., 2003; Olschowka et al., 2003). (In contrast, microinjection of helper viruscontaining HSV-1 vectors, an older vector system that was not used in this study, elicits a significant immune response [Wood et al., 1994].)

\section{4-gene-vector supports long-term expression of human GTP CH I RNA and protein}

Striata were isolated 4 days, 1 month, 6 months, or 12 months after microinjection of the 4gene-vector. RNA was extracted from these striata, RT-PCR was performed with primers specific for the recombinant, human GTP CH I gene, and the reaction products were separated on an agarose gel. The results (Fig. 7A) showed the predicted 386-bp band in RT-PCRs that used RNA obtained from striata harvested at 4 days, 1 month, 6 months, or 12 months after microinjection of the 4-genevector (lanes 1-4, respectively). No band was observed in an RTPCR that did not contain an RNA sample (Fig. 7A, lane 5). Also, no band was observed in an RT-PCR that contained RNA isolated from the striatum of a normal rat (no lesion, no gene transfer; Fig. 7A, lane 6); thus, endogenous rat GTP CH I RNA is not recognized by the human GTP CH I-specific primers used in this assay. In addition, no band was observed in a reaction that lacked reverse transcriptase and contained RNA from a striatum that received the 4-gene- 
vector and was harvested 4 days after gene transfer (Fig. 7A, lane 7); thus, the signal is from RNA and not from contaminating DNA. As a positive control, the predicted 386-bp band was detected in a reaction that contained 4-gene-vector plasmid DNA isolated from E. coli (Fig. 7A, lane 8).

Rats killed either 4 days or 6 months after gene transfer with the 4-gene-vector contained GTP CH I-IR-positive striatal cell bodies near the injection sites (Fig. 7B and C). Most of the GTP CH I-IR was in cell bodies, and because GTP CH I is the second gene in the ha-vmat/ires/gtpch cassette, the levels of GTP CH I expression may be somewhat lower. No GTP CH I-IR-positive cell bodies were observed at locations within the striatum but distant from the injection sites. This antibody is panspecific and also recognizes the endogenous rat GTP CH I (Pluss et al., 1996). However, GTP CH I RNA is found only in monoaminergic neurons and has not been detected in striatal cells (Hirayama et al., 1993). Nigrostriatal dopaminergic neurons contain lower levels of GTP CH I RNA and protein than are found in either noradrenergic or serotonin neurons (Hirayama et al., 1993; Hirayama and Kapatos, 1998). Using a different antibody, GTP CH I-IR was reported in nigrostriatal neuron cell bodies in the SNc, but was not detected in striatal processes (Hirayama and Kapatos, 1998), similar to our results (Fig. 7B and C). Thus, the GTP CH I-IR-positive striatal cell bodies located near the injection sites (Fig. 7B and C) may indicate expression of recombinant human GTP CH I protein, and are consistent with both expression of human GTP CH I RNA in striatal cells (Fig. 7A) and expression of recombinant GTP CH I protein in cultured fibroblasts (Fig. 2B).

\section{Coexpression of dopamine biosynthetic and transporter proteins supports correction of apomorphine-induced rotational behavior in the 6-OHDA rat model of PD}

Rats were lesioned with 6-OHDA under standard conditions (Perese et al., 1989). Rats with relatively complete 6-OHDA lesions (more than five turns per minute) were identified by measuring apomorphine-induced rotational behavior (three to five times, at weekly intervals). This rotation rate is consistent with a $\geq 90 \%$ reduction in the number of nigrostriatal neurons (Hefti et al., 1980a; Carman et al., 1991). The extent of the 6-OHDA lesions was verified in selected rats, killed at specific times after gene transfer, by staining sections that contained the midbrain or the striatum for TH-IR. In a rat killed 1.5 months after lesioning, large numbers of TH-IR cell bodies and processes were found in the substantia nigra on the contralateral, unlesioned side, but few TH-IR-positive cells or processes were detected on the lesioned side (Fig. 8A). Also, the striatum on the unlesioned side, but not the lesioned side, contained large numbers of TH-IR-positive processes (Fig. 8B).

Rats with relatively complete lesions were used for gene transfer. The 3-gene-vector, the 4gene-vector, or controls (lacZ-vector or PBS) were microinjected into each of three sites in the partially denervated striatum; these injection sites have been used in previous studies to correct the rat model of PD (During et al., 1994; Sun et al., 2003). Starting 3 weeks after gene transfer, the rats were tested for apomorphine-induced rotational behavior at weekly intervals for 2 months, and then every other week until the rats were killed. Before gene transfer, there were no significant differences in the rotation rates between rats in the four different groups (3-genevector, 4-gene-vector, lacZ-vector, PBS), as shown by a between-group ANOVA (Fig. 9; $p=$ $0.65)$. In contrast, after gene transfer, rats that received either the 3-gene-vector or the 4-genevector displayed significant (50 to $80 \%$ ) reductions in apomorphine-induced rotational behavior compared with rats in the two control groups, and these reductions were maintained for 6 months; there were significant differences in the rotation rates between rats in the four different groups, as shown by a between-group ANOVA (Fig. 9; $p<0.001$ ). Subsequent pairwise multiple comparisons (Tukey test) showed that there was no significant difference between the two control groups (lacZ-vector versus PBS, $p>0.05$ ). However, there were significant differences when comparing either the 3-gene-vector or the 4-gene-vector with 
either control group (4-gene-vector versus lacZ-vector or PBS, $p<0.001$; 3-gene-vector versus lacZ-vector, $p<0.01 ; 3$-gene-vector versus PBS, $p<0.01)$. Moreover, rats that received the 4 -gene-vector displayed a larger reduction in apomorphine-induced rotational behavior than those that received the 3-gene-vector (Fig. 9; $p<0.05$ ).

\section{Coexpression of dopamine biosynthetic and transporter proteins supports $\mathrm{K}^{+}$-dependent release of high levels of dopamine}

In vivo microdialysis was used to measure extracellular levels of $\mathrm{L}-\mathrm{DOPA}$, dopamine, and DOPAC in the striatum near the injection sites. At an average of 3 months after gene transfer, in specific rats, cannulas were implanted between the three injection sites used for gene transfer. Two to 3 days later, microdialysates were collected from awake, freely moving rats by perfusion with artificial CSF containing low $\mathrm{K}^{+}\left(2.7 \mathrm{~m} M \mathrm{~K}^{+}\right)$, followed by artificial CSF containing high $\mathrm{K}^{+}\left(56 \mathrm{mM} \mathrm{K}^{+}\right)$. The levels of $\mathrm{L}_{-}$-DOPA, dopamine, and DOPAC in each sample were quantified by HPLC followed by electrochemical detection (Holmes et al., 1994; Yadid et al., 2000).

In vivo microdialysis was performed on specific rats that received the 3-gene-vector or the 4gene-vector, control rats (6-OHDA lesion, microinjection of either the lacZ-vector or PBS), and normal rats (unlesioned, no gene transfer). There were significant differences between the rats in the different groups (3-gene-vector, 4-gene-vector, controls, normal) in the levels of each of the three catecholamines, under both low- $\mathrm{K}^{+}$and high- $\mathrm{K}^{+}$conditions, as shown by six between-group ANOVAs (Fig. 10; L-DOPA, dopamine, or DOPAC; low $\mathrm{K}^{+}$or high $\mathrm{K}^{+}$for each catecholamine, $p<0.05$ ). These differences were subsequently analyzed in pairwise multiple comparisons. Control rats exhibited extracellular levels of $\mathrm{L}-\mathrm{DOPA}$, dopamine, and DOPAC that were $2-12 \%$ of the levels observed in normal rats, under high- $\mathrm{K}^{+}$conditions (Fig. $10 ; p<0.05)$. $\mathrm{A} \geq 90 \%$ reduction in striatal dopamine levels is consistent with 6-OHDA lesions that ablate $\geq 90 \%$ of the nigrostriatal neurons (Hefti et al., 1980b). Rats that received the 3gene-vector displayed a 350\% increase in DOPAC levels, which approached significance, compared with the levels in control rats, under high- $\mathrm{K}^{+}$conditions (Fig. 10; $p=0.08$ ), but the DOPAC levels were not increased under low- $\mathrm{K}^{+}$conditions $(p>0.05)$, and the levels of $\mathrm{L}^{-}$ DOPA and do-pamine were similar in these two groups, under both low- $\mathrm{K}^{+}$and high- $\mathrm{K}^{+}$ conditions $(p>0.05)$. In contrast to the results with the 3-gene-vector, rats that received the 4gene-vector displayed 180 to $3500 \%$ increases in the levels of $\mathrm{L}$-DOPA, dopamine, and DOPAC compared with the levels observed in control rats, under both low- $\mathrm{K}^{+}$and high- $\mathrm{K}^{+}$conditions (Fig. 10,4-gene-vector versus control rats: Low $\mathrm{K}^{+}$: L-DOPA or dopamine, $p<0.05$; DOPAC, $p<0.001$. High K ${ }^{+}$: ${ }_{\text {LDOPA, }} p<0.05$; dopamine, $p<0.01$; DOPAC, $p<0.001$ ). Moreover, rats that received the 4-gene-vector displayed 200 to $1000 \%$ increases in the levels of $\mathrm{L}-\mathrm{DOPA}$, dopamine, and DOPAC compared with the levels observed in rats that received the 3-genevector, under both low- $\mathrm{K}^{+}$and high- $\mathrm{K}^{+}$conditions (4-gene-vector versus 3-gene-vector: Low $\mathrm{K}^{+}$: L-DOPA, $p<0.05$; dopamine, $p<0.01$; DOPAC, $p<0.05$. High $\mathrm{K}^{+}$: ${ }_{\text {L-DOPA, }} p<0.01$; dopamine, $p<0.02$; DOPAC, $p<0.01$ ). Of note, rats that received the 4-gene-vector displayed similar levels of dopamine and DOPAC compared with the levels observed in normal rats, under both low- $\mathrm{K}^{+}$and high- $\mathrm{K}^{+}$conditions (4-gene-vector versus normal rats: low $\mathrm{K}^{+}$or high $\mathrm{K}^{+}$, dopamine or DOPAC, $p>0.05$ ); however, levels of ${ }_{\mathrm{L}}$ DOPA in the 4-gene-vector group remained below those observed in the normal group, under both low- $\mathrm{K}^{+}$and high- $\mathrm{K}^{+}$ conditions (low $\mathrm{K}^{+}$or high $\mathrm{K}^{+}, p<0.05$ ). Furthermore, in rats that received the 4-gene-vector, but not the 3-gene-vector, the high- $\mathrm{K}^{+}$condition caused a $1200 \%$ increase in the levels of extracellular dopamine (low $\mathrm{K}^{+}$versus high $\mathrm{K}^{+}: 3$-gene-vector, $p>0.05$; 4-gene-vector, $p<$ $0.05)$. This large, high $\mathrm{K}^{+}$-dependent increase in dopamine levels is consistent with regulated, vesicular release of dopamine, and only the 4-gene-vector expresses VMAT-2. Also, in the 4gene-vector group, the high- $\mathrm{K}^{+}$condition caused a modest $200 \%$ increase in the low levels of L-DOPA $(p<0.05)$ and did not significantly increase levels of DOPAC $(p>0.05)$. Consistent 
with these results, VMAT-2 does not sequester either L-DOPA or DOPAC into synaptic vesicles (Johnson, 1988;Liu et al., 1992). In these experiments, the dialysis probe was placed near the three injection sites; ex-tracellular striatal catecholamine levels at striatal locations distant from the injection sites were not measured, but were likely much lower than those near the injection sites.

\section{DISCUSSION}

In this study, we compared vectors that coexpress three do-pamine biosynthetic enzymes (TH, GTP CH I, and AADC; 3-gene-vector) or these three dopamine biosynthetic enzymes and a vesicular monoamine transporter (4-gene-vector) for correction of the rat model of PD. Both vectors supported the production of dopamine in cultured cells, coexpression of the predicted gene products in GABA-ergic striatal neurons, and long-term expression (14 months). Both vectors supported long-term (6 months) correction of apomorphine-induced rotational behavior in the rat model of PD. Of note, the 4-gene-vector supported higher levels of this correction than did the 3-gene-vector. Also, only the 4-gene-vector supported extracellular levels of both dopamine and DOPAC that approached the levels observed in normal rats, and high $\mathrm{K}^{+}$-dependent release of dopa-mine. These results suggest that coexpression of a vesicular monoamine transporter with specific dopamine biosynthetic enzymes may provide significant benefits for restoring striatal do-pamine levels in potential gene therapy treatments for PD.

\section{Recombinant gene expression}

The 3-gene-vector and the 4-gene-vector both contain two transcription units: a neuron-specific promoter, the INS-TH-NFH promoter (Zhang et al., 2000), supports expression from both transcription units. The 3-gene-vector and the 4-gene-vector supported expression of the three or four predicted proteins, respectively, in cultured fibroblasts. After microinjection of the 4gene-vector into rat striatum, human GTP CH I RNA was detected in rats killed 4 days, 1 month, 6 months, or 12 months after gene transfer; FLAG-TH, human AADC, and HAVMAT- 2 proteins were detected in rats killed at 4 days, 5 months, 8 months, or 14 months; and GTP CH I-IR-positive cell bodies were detected near the injection sites in rats killed at either 4 days or 6 months. In rats killed either 4 days or 14 months after gene transfer, two genes located either before or after an IRES (FLAG-TH and human AADC) were coexpressed in the same cells, and specific genes from each of the two transcription units (human AADC and HA-VMAT-2) were coexpressed in the same cells. Neuron-specific expression of human AADC was observed in rats killed either 4 days or 14 months after gene transfer, and GABAergic neuron-specific expression of FLAG-TH was observed in rats killed either 4 days or 6 months after gene transfer. Three rats killed 5-6 months after gene transfer contained an average of 11,400 FLAG-TH-positive stri-atal cells per rat, and a time course showed that the INS-TH-NFH promoter supports expression in similar numbers of stri-atal cells in rats killed 2 weeks, or 1, 2, 4, or 6 months, after gene transfer (Zhang et al., 2000). Although the expression data shown in this study were based on use of the 4-gene-vector, similar ABC and immunofluorescence staining was observed with the 3-gene-vector; however, no cell counts were performed with this staining. Taken together, these results suggest that after microinjection of these vectors, the predicted gene products were coexpressed in $\sim 11,400$ predominantly GABA-ergic stri-atal neurons for at least 6 months, and significant levels of expression were maintained for 14 months.

The number of cells that contain recombinant gene products reported here is similar to that reported in other studies that co-expressed specific dopamine biosynthetic enzymes to correct the rat model of PD. A lentiviral vector coexpressed TH, GTP CH I, and AADC in 5000 cells 10 weeks or 5 months after gene transfer (Azzouz et al., 2002). Coinjection of two AAV vectors that express either TH or GTP CH supported $\sim 4000$ or $\sim 1000$ TH-positive cells at 3 weeks or 
6 months, respectively (Mandel et al., 1998). An adenoviral vector expressed TH in 5000 to 10,000 cells at 2.5 to 17 weeks (Corti et al., 1999). However, two studies report expression in more cells; coinjec-tion of three AAV vectors that express TH, GTP CH I, or AADC supported expression in 20,000 to 40,000 striatal cells at 7 months (Shen et al., 2000), and coinjection of two AAV vectors at five sites resulted in 320,000 to 350,000 positive cells at 3 weeks (Kirik et al., 2002).

These HSV-1 vectors contain a neuron-specific, modified neurofilament heavy gene promoter, but the lentivirus and AAV vectors contain constitutive promoters. Using specific lentivirus or AAV vectors that contain the cytomegalovirus immediate-early (CMV IE) promoter, expression was localized to either neurons or GABA-ergic neurons (Mandel et al., 1998; Shen et al., 2000; Azzouz et al., 2002). Also, an AAV vector that contains a CMV IE enhancer/Bactin promoter supported expression in cells with medium spiny neuron morphology (Kirik et al., 2002). Paradoxically, in the brains of transgenic mice, the CMV IE promoter supports expression predominantly in specific types of nonneuronal cells, and in only a few specific subtypes of neurons (Fritschy et al., 1996), and $\beta$-actin is present in many cell types. The INSTH-NFH promoter used here is based on the neuron-specific NFH gene promoter, and supports long-term expression in forebrain neurons (Zhang et al., 2000).

Treatment of PD required precise control of striatal dopa-mine levels; thus, further development of this approach (discussed below) may require large vectors that use inducible and cell type-specific promoters to precisely control expression of multiple genes. Coinjection of two or three different AAV vectors that express different genes (Mandel et al., 1998; Shen et al., 2000; Kirik et al., 2002) likely results in some cells that do not receive all the genes, and some cells that receive different numbers of specific genes. One lentiviral vector can coexpress three genes (TH, GTP CH I, and AADC; Azzouz et al., 2002), but addition of more genes may challenge the $\sim 11-\mathrm{kb}$ capacity of lentiviral vectors. Attractive characteristics of AAV and lentiviral vectors include minimal side effects and long-term expression in large numbers of neurons (Kordower et al., 2000; Kirik et al., 2002). In contrast, adenovirus and HSV-1 vectors have large capacities. However, most adenoviral vectors cause cytopathic effects and elicit a significant immune response. Helper virus-free HSV-1 vectors cause minimal side effects and support long-term expression from neuron-specific promoters, but require significantly higher titers and other improvements. Thus, future advances will likely continue to use the vector system best suited for the particular experiment.

\section{Coexpression of VMAT with dopamine biosynthetic enzymes supports high $\mathrm{K}^{+}$-dependent release of significant levels of dopamine}

The 3-gene-vector, which coexpresses three dopamine biosynthetic genes (TH, GTP CH I, and AADC), did not support significant increases in the extracellular levels of ${ }_{\text {L-DOPA, dopamine, }}$ or DOPAC. Similarly, a study that used a lentiviral vector to coexpress these same three dopamine biosynthetic genes, in similar numbers of cells, reported no significant increases in production of dopamine or DOPAC in striatal tissue punches (Azzouz et al., 2002). However, a study that coinjected $3 \mathrm{AAV}$ vectors that express these 3 genes reported increased production of dopamine in striatal tissue punches, but required expression in $\sim 30$-fold more cells (Shen et al., 2000).

In contrast, the 4-gene-vector, which coexpresses these three dopamine biosynthetic genes and a vesicular monoamine transporter (TH, GTP CH I, AADC, and VMAT-2), supported extracellular levels of dopamine and DOPAC that were similar to those observed in the striatum of normal rats. In cultured fibroblasts, which lack a synaptic vesicle compartment, the 4-genevector did not increase production of catecholamines compared with the 3-gene-vector. These results are consistent with VMAT-2-mediated transport of dopamine into synaptic vesicles in striatal neurons. The resulting lower cytoplasmic levels of dopamine will reduce feedback 
inhibition of TH by dopa-mine (Fitzpatrick, 1999), supporting production of more catecholamines. Of note, in the striatum, the 4-gene-vector supported large, high $\mathrm{K}^{+}$-dependent increases in the extracellular levels of dopamine, but not of ${ }_{\mathrm{L}}$-DOPA or DOPAC. Consistent with these results, VMAT-2 supports the transport of dopamine, but not of $\mathrm{L}-\mathrm{DOPA}$ or DOPAC, into synaptic vesicles (Johnson, 1988; Liu et al., 1992). Thus, the large, high $\mathrm{K}^{+}$-dependent increases in extracellular dopamine levels suggest neurotransmitter release from synaptic vesicles, and are not consistent with unregulated, constitutive secretion of catecholamines from the cytoplasm. Recombinant gene expression occurred predominantly in GABA-ergic medium spiny striatal neurons, and presumably dopamine was produced in these GABA-ergic neurons, thereby violating the principle of one classic neurotrans-mitter per neuron. Future studies will be required to determine whether dopamine is coreleased with GABA, to directly determine whether dopamine is present in synaptic vesicles, and, if so, to determine whether GABA and dopamine are present in the same, or different, populations of synaptic vesicles. Dopamine can be released from the cell body and dendrites of nigrostriatal neurons (Nissbrandt et al., 1989; Robertson et al., 1991), and most of the antibody staining was localized to the cell body and proximal processes of striatal neurons, suggesting that dopamine was released from the cell bodies and proximal processes of the transfected neurons, within the striatum. However, striatal neurons project to specific brain areas, and future studies will be required to determine whether dopamine is also released from the axon terminals of transfected striatal neurons. Extracellular catecholamine levels were measured near the injection sites, and long-term recombinant gene expression was observed in only $\sim 0.4 \%$ of the $2.79 \times 10^{6}$ striatal neurons (Oorschot, 1996). However, dopamine diffuses significant distances in the striatum (Schmitz et al., 2003), and the majority of dopamine receptors are extrasynaptic (Hersch et al., 1995). Moreover, dopamine diffuses further in the partially denervated striatum, as plasma membrane dopamine transporters (found only on dopaminergic nigrostriatal neuron processes in the striatum; Hersch et al., 1997) are largely absent. Thus, it appears likely that significantly more than $0.4 \%$ of the striatal neurons were affected by the dopamine produced by the recombinant enzymes.

Nonetheless, higher titers of these HSV-1 vectors will be required to restore dopamine levels throughout the striatum.

\section{Future directions}

Current treatments of PD illustrate the importance of precise control of striatal dopamine levels. Consequently, human gene therapy for PD may require inducible and cell type-specific coexpression of multiple dopamine biosynthetic and transport genes. Efficient production of the cofactor for $\mathrm{TH}$ may require coexpression of the three genes in the $\mathrm{BH}_{4}$ biosynthetic pathway (Fig. 1A; GTP CH I, 6-pyruvoyltetrahydropterin synthase, and sepiapterin reductase). Higher levels of striatal dopamine might be achieved by coexpression of both a VMAT and a plasma membrane dopamine transporter, to support reuptake and rerelease of dopamine. Control of the levels of dopamine biosynthetic enzymes may require an inducible promoter, such as the tetracycline-inducible promoter. One particular type of striatal neuron may be the preferred site for dopamine production. In particular, the two principal types of GABA-ergic medium spiny striatal neurons have different physiological properties; thus, neuronal subtype-specific promoters, such as peptide neurotransmitter gene promoters, may target expression to the preferred type of striatal neuron.

Current treatments of Parkinson's disease do not support precise control over the delivery of dopamine to striatal dopamine receptors. The results in this report suggest that coexpression of multiple dopamine biosynthetic and transport genes may support the regulation not only of dopamine production, but also of dopamine release. 


\section{Acknowledgements}

We gratefully thank Dr. Karen L. O'Malley for cassettes containing specific combinations of TH, GTP CH I, and AADC, and the TH promoter; Dr. Robert H. Edwards for VMAT-2 cDNA; Dr. John W. Haycock for anti-AADC antibody; Dr. An-drew J. Davison for HSV-1 cosmid set C; Dr. Rozanne M. San-dri-Goldin for 2-2 cells; Dr. William W. Schlaepfer for the NFH promoter; and Dr. Gary Felsenfeld for the $\beta$-globin insulator. This work was supported by AG20177 and the National Parkin-son Foundation/Parkinson's Disease Foundation (M.S.); and by AG16777, NS42016, NS045855, and AG021193 (A.G.).

\section{References}

AZZOUZ M, MARTIN-RENDON E, BARBER RD, MITRO-PHANOUS KA, CARTER EE, ROHLL JB, KINGSMAN SM, KINGSMAN AJ, MAZARAKIS ND. Multi-cistronic lentiviral vectormediated striatal gene transfer of aromatic l-amino acid decarboxylase, tyrosine hydroxylase, and GTP cyclohydrolase I induces sustained transgene expression, dopamine production, and functional improvement in a rat model of Parkinson's disease. J Neurosci 2002;22:10302-10312. [PubMed: 12451130]

BARKER RA, DUNNETT SB. Functional integration of neural grafts in Parkinson's disease. Nat Neurosci 1999;2:1047-1048. [PubMed: 10570477]

BENCSICS C, WACHTEL SR, MILSTIEN S, HATAKEYAMA K, BECKER JB, KANG UJ. Double transduction with GTP cyclohydrolase I and tyrosine hydroxylase is necessary for spontaneous synthesis of 1-DOPA by primary fibroblasts. J Neurosci 1996;16:4449-4456. [PubMed: 8699255]

BJORKLUND A, KIRIK D, ROSENBLAD C, GEORGIEVSKA B, LUNDBERG C, MANDEL RJ. Towards a neuroprotective gene therapy for Parkinson's disease: Use of adenovirus, AAV and lentivirus vectors for gene transfer of GDNF to the nigrostriatal system in the rat Parkinson model. Brain Res 2000;886:82-98. [PubMed: 11119690]

BOWERS WJ, OLSCHOWKA JA, FEDEROFF HJ. Immune responses to replication-defective HSV-1 type vectors within the CNS: Implications for gene therapy. Gene Ther 2003;10:941-945. [PubMed: 12756414]

CARMAN LS, GAGE FH, SHULTS CW. Partial lesion of the substantia nigra: Relation between extent of lesion and rotational behavior. Brain Res 1991;553:275-283. [PubMed: 1681983]

CHOI-LUNDBERG DL, LIN Q, CHANG YN, CHIANG YL, HAY CM, MOHAJERI H, DAVIDSON $\mathrm{BL}, \mathrm{BOHN}$ MC. Dopaminergic neurons protected from degeneration by GDNF gene therapy. Science 1997;275:838-841. [PubMed: 9012352]

CORTI O, SANCHEZ-CAPELO A, COLIN P, HANOUN N, HA-MON M, MALLET J. Long-term doxycycline-controlled expression of human tyrosine hydroxylase after direct ade-novirus-mediated gene transfer to a rat model of Parkinson's disease. Proc Natl Acad Sci USA 1999;96:12120-12125. [PubMed: 10518586]

DURING MJ, NAEGELE JR, O’MALLEY KL, GELLER AI. Long-term behavioral recovery in parkinsonian rats by an HSV vector expressing tyrosine hydroxylase. Science 1994;266:1399-1403. [PubMed: 7669103]

FITZPATRICK PF. Tetrahydropterin-dependent amino acid hydroxylases. Annu Rev Biochem 1999;68:355-381. [PubMed: 10872454]

FRAEFEL C, SONG S, LIM F, LANG P, YU L, WANG Y, WILD P, GELLER AI. Helper virus-free transfer of herpes simplex virus type 1 plasmid vectors into neural cells. J Vi-rol 1996;70:7190-7197.

FREED CR, GREENE PE, BREEZE RE, TSAI WY, DU-MOUCHEL W, KAO R, DILLON S, WINFIELD H, CULVER S, TROJANOWSKI JQ, EIDELBERG D, FAHN S. Transplantation of embryonic dopamine neurons for severe Parkin-son's disease. N Engl J Med 2001;344:710-719. [PubMed: 11236774]

FREESE A, GELLER AI, NEVE R. HSV-1 vector mediated neuronal gene delivery: Strategies for molecular neuroscience and neurology. Biochem Pharmacol 1990;40:2189-2199. [PubMed: 2173924]

FRITSCHY JM, BRANDNER S, AGUZZI A, KOEDOOD M, LUSCHER B, MITCHELL PJ. Brain cell type specificity and gliosis-induced activation of the human cytomegalovirus immediate-early promoter in transgenic mice. J Neurosci 1996;16:2275-2282. [PubMed: 8601807] 
GAGE FH. Cell therapy. Nature 1998;392(Suppl):18-24. [PubMed: 9579857]

GELLER AI, DURING MJ, OH YJ, FREESE A, O'MAL-LEY K. An HSV-1 vector expressing tyrosine hydroxylase causes production and release of 1 -dopa from cultured rat striatal cells. J Neurochem 1995;64:487-496. [PubMed: 7830040]

HEFTI F, MELAMED E, SAHAKIAN BJ, WURTMAN RJ. Circling behavior in rats with partial, unilateral nigro-striatal lesions: Effect of amphetamine, apomorphine, and DOPA. Pharmacol Biochem Behav 1980a;12:185-188. [PubMed: 7189592]

HEFTI F, MELAMED E, WURTMAN RJ. Partial lesions of the dopaminergic nigrostriatal system in rat brain: Biochemical characterization. Brain Res 1980b;195:123-137. [PubMed: 6105003]

HERSCH SM, CILIAX BJ, GUTEKUNST CA, REES HD, HEILMAN CJ, YUNG KK, BOLAM JP, INCE E, YI H, LEVEY AI. Electron microscopic analysis of D1 and D2 dopamine receptor proteins in the dorsal striatum and their synaptic relationships with motor corticostriatal afferents. J Neurosci 1995;15:5222-5237. [PubMed: 7623147]

HERSCH SM, YI H, HEILMAN CJ, EDWARDS RH, LEVEY AI. Subcellular localization and molecular topology of the dopamine transporter in the striatum and substantia nigra. J Comp Neurol 1997;388:211-227. [PubMed: 9368838]

HIRAYAMA K, KAPATOS G. Nigrostriatal dopamine neurons express low levels of GTP cyclohydrolase I protein. J Neurochem 1998;70:164-170. [PubMed: 9422359]

HIRAYAMA K, LENTZ SI, KAPATOS G. Tetrahydrobiopterin cofactor biosynthesis: GTP cyclohydrolase I mRNA expression in rat brain and superior cervical ganglia. J Neurochem 1993;61:1006-1014. [PubMed: 8103077]

HOLMES C, EISENHOFER G, GOLDSTEIN DS. Improved assay for plasma dihydroxyphenylacetic acid and other catechols using high-performance liquid chromatography with electrochemical detection. J Chromatogr B Biomed Appl 1994;653:131-138. [PubMed: 8205240]

HYMAN C, HOFER M, BARDE YA, JUHASZ M, YAN-COPOULOS GD, SQUINTO SP, LINDSAY RM. BDNF is a neurotrophic factor for dopaminergic neurons of the sub-stantia nigra. Nature 1991;350:230-232. [PubMed: 2005978]

ISACSON O. Behavioral effects and gene delivery in a rat model of Parkinson's disease. Science 1995;269:856-857. [PubMed: 7638605]

JOHNSON RG JR. Accumulation of biological amines into chromaffin granules: A model for hormone and neurotransmitter transport. Physiol Rev 1988;68:232-307. [PubMed: 2892215]

KANG UJ, FISHER LJ, JOH TH, O’MALLEY KL, GAGE FH. Regulation of dopamine production by genetically modified primary fibroblasts. J Neurosci 1993;13:5203-5211. [PubMed: 7902865]

KANG UJ, LEE WY, CHANG JW. Gene therapy for Parkinson's disease: Determining the genes necessary for optimal dopamine replacement in rat models. Hum Cell 2001;14:39-48. [PubMed: 11436352]

KIRIK D, ROSENBLAD C, BJORKLUND A, MANDEL RJ. Long-term rAAV-mediated gene transfer of GDNF in the rat Parkinson's model: Intrastriatal but not intranigral transduction promotes functional regeneration in the lesioned nigrostriatal system. J Neurosci 2000;20:4686-4700. [PubMed: 10844038]

KIRIK D, GEORGIEVSKA B, BURGER C, WINKLER C, MUZYCZKA N, MANDEL RJ, BJORKLUND A. Reversal of motor impairments in parkinsonian rats by continuous intrastriatal delivery of 1 -dopa using rAAV-mediated gene transfer. Proc Natl Acad Sci USA 2002;99:47084713. [PubMed: 11917105]

KORDOWER JH, EMBORG ME, BLOCH J, MA SY, CHU Y, LEVENTHAL L, McBRIDE J, CHEN EY, PALFI S, ROITBERG BZ, BROWN WD, HOLDEN JE, PYZALSKI R, TAYLOR MD, CARVEY P, LING Z, TRONO D, HANTRAYE P, DEGLON N, AEBISCHER P.

Neurodegeneration prevented by lentiviral vector delivery of GDNF in primate models of Parkinson's disease. Science 2000;290:767-773. [PubMed: 11052933]

LEE WY, CHANG JW, NEMETH NL, KANG UJ. Vesicular monoamine transporter-2 and aromatic 1amino acid de-carboxylase enhance dopamine delivery after 1-3,4-dihydroxyphen-ylalanine administration in Parkinsonian rats. J Neurosci 1999;19:3266-3274. [PubMed: 10191339] 
LIM F, HARTLEY D, STARR P, LANG P, SONG S, YU L, WANG Y, GELLER AI. Generation of high-titer defective HSV-1 vectors using an IE 2 deletion mutant and quantitative study of expression in cultured cortical cells. Biotechniques 1996;20:460-469. [PubMed: 8679207]

LIN LF, DOHERTY DH, LILE JD, BEKTESH S, COLLINS F. GDNF: A glial cell line-derived neurotrophic factor for midbrain dopaminergic neurons. Science 1993;260:1130-1132. [PubMed: 8493557]

LINDVALL O, BRUNDIN P, WIDNER H, REHNCRONA S, GUSTAVII B, FRACKOWIAK R, LEENDERS KL, SAWLE G, ROTHWELL JC, MARSDEN CD, et al. Grafts of fetal dopamine neurons survive and improve motor function in Parkinson's disease. Science 1990;247:574-577. [PubMed: 2105529]

LIU Y, PETER D, ROGHANI A, SCHULDINER S, PRIVE GG, EISENBERG D, BRECHA N, EDWARDS RH. A cDNA that suppresses MPP + toxicity encodes a vesicular amine transporter. Cell 1992;70:539-551. [PubMed: 1505023]

MANDEL RJ, RENDAHL KG, SPRATT SK, SNYDER RO, COHEN LK, LEFF SE. Characterization of intrastri-atal recombinant adeno-associated virus-mediated gene transfer of human tyrosine hydroxylase and human GTP-cyclohydrolase I in a rat model of Parkinson's disease. J Neurosci 1998;18:4271-4284. [PubMed: 9592104]

MANIATIS, T., FRITSCH, E.F., and SAMBROOK, J. (1989). Molecular Cloning, 2nd ed. (Cold Spring Harbor Laboratory Press, Cold Spring Harbor, NY).

MOFFAT M, HARMON S, HAYCOCK J, O'MALLEY KL. 1 -Dopa and dopamine-producing gene cassettes for gene therapy approaches to Parkinson's disease. J Neurochem 1997;68:1792-1803. [PubMed: 9109503]

MULLEN RJ, BUCK CR, SMITH AM. NeuN, a neuronal specific nuclear protein in vertebrates. Development 1992;116:201-211. [PubMed: 1483388]

MURAMATSU S, FUJIMOTO K, IKEGUCHI K, SHIZUMA N, KAWASAKI K, ONO F, SHEN Y, WANG L, MIZUKAMI H, KUME A, MATSUMURA M, NAGATSU I, URANO F, ICHINOSE H, NAGATSU T, TERAO K, NAKANO I, OZAWA K. Behavioral recovery in a primate model of Parkinson's disease by triple transduction of striatal cells with adeno-associated viral vectors expressing dopamine-synthesizing enzymes. Hum Gene Ther 2002;13:345-354. [PubMed: 11860702]

NISSBRANDT H, SUNDSTROM E, JONSSON G, HJORTH S, CARLSSON A. Synthesis and release of dopamine in rat brain: Comparison between substantia nigra pars compacts, pars reticulata, and striatum. J Neurochem 1989;52:1170-1182. [PubMed: 2564423]

NOMURA T, OHTSUKI M, MATSUI S, SUMI-ICHINOSE C, NOMURA H, HAGINO Y, IWASE K, ICHINOSE H, FUJITA K, NAGATSU T. Isolation of a full-length cDNA clone for human GTP cyclohydrolase I type 1 from pheochromocytoma. J Neural Transm Gen Sect 1995;101:237-242. [PubMed: 8695054]

OLSCHOWKA JA, BOWERS WJ, HURLEY SD, MAS-TRANGELO MA, FEDEROFF HJ. Helperfree HSV-1 amplicons elicit a markedly less robust innate immune response in the CNS. Mol Ther 2003;7:218-227. [PubMed: 12597910]

OORSCHOT DE. Total number of neurons in the neostriatal, pallidal, subthalamic, and substantia nigral nuclei of the rat basal ganglia: A stereological study using the Cavalieri and optical disector methods. J Comp Neurol 1996;366:580-599. [PubMed: 8833111]

PAXINOS, G., and WATSON, C. (1986). The Rat Brain in Stereotaxic Coordinates (Academic Press, Sydney, Australia).

PERESE DA, ULMAN J, VIOLA J, EWING SE, BANKIEWICZ KS. A 6-hydroxydopamine-induced selective parkinsonian rat model. Brain Res 1989;494:285-293. [PubMed: 2528389]

PICCINI P, BROOKS DJ, BJORKLUND A, GUNN RN, GRASBY PM, RIMOLDI O, BRUNDIN P, HAGELL P, REHNCRONA S, WIDNER H, LINDVALL O. Dopamine release from nigral transplants visualized in vivo in a Parkinson's patient. Nat Neurosci 1999;2:1137-1140. [PubMed: 10570493]

PLUSS C, WERNER ER, BLAU N, WACHTER H, PFEILSCHIFTER J. Interleukin $1 \beta$ and cAMP trigger the expression of GTP cyclohydrolase I in rat renal mesangial cells. Biochem J 1996;318:665671. [PubMed: 8809061] 
ROBERTSON GS, DAMSMA G, FIBIGER HC. Characterization of dopamine release in the substantia nigra by in vivo microdialysis in freely moving rats. J Neurosci 1991;11:2209-2216. [PubMed: 1712381]

SCHMITZ Y, BENOIT-MARAND M, GONON F, SULZER D. Presynaptic regulation of dopaminergic neurotransmission. J Neurochem 2003;87:273-289. [PubMed: 14511105]

SHEN Y, MURAMATSU SI, IKEGUCHI K, FUJIMOTO KI, FAN DS, OGAWA M, MIZUKAMI H, URABE M, KUME A, NAGATSU I, URANO F, SUZUKI T, ICHINOSE H, NA-GATSU T, MONAHAN J, NAKANO I, OZAWA K. Triple transduction with adenoassociated virus vectors expressing tyrosine hydroxylase, aromatic- 1 -amino-acid decarboxylase, and GTP cyclohydrolase I for gene therapy of Parkinson's disease. Hum Gene Ther 2000;11:1509-1519. [PubMed: 10945765]

SMITH IL, HARDWICKE MA, SANDRI-GOLDIN RM. Evidence that the herpes simplex virus immediate early protein ICP27 acts post-transcriptionally during infection to regulate gene expression. Virology 1992;186:74-86. [PubMed: 1309283]

SONG S, WANG Y, BAK SY, LANG P, ULLREY D, NEVE RL, O’MALLEY KL, GELLER AI. An HSV-1 vector containing the rat tyrosine hydroxylase promoter enhances both long-term and cell type-specific expression in the midbrain. J Neurochem 1997;68:1792-1803. [PubMed: 9109503]

SUN M, ZHANG GR, YANG T, YU L, GELLER AI. Improved titers for helper virus-free herpes simplex virus type 1 plasmid vectors by optimization of the packaging protocol and addition of noninfectious herpes simplex virus-related particles (pre-viral DNA replication enveloped particles) to the packaging procedure. Hum Gene Ther 1999;10:2005-2011. [PubMed: 10466634]

SUN M, ZHANG G, KONG L, HOLMES C, WANG X, ZHANG W, GOLDSTEIN DS, GELLER AI. Correction of a rat model of Parkinson's disease by coexpression of tyrosine hydroxylase and aromatic amino acid decarboxylase from a helper virus-free herpes simplex virus type 1 vector. Hum Gene Ther 2003;14:415-424. [PubMed: 12691607]

TASHIRO Y, KANEKO T, SUGIMOTO T, NAGATSU I, KIKUCHI H, MIZUNO N. Striatal neurons with aromatic 1 -amino acid decarboxylase-like immunoreactivity in the rat. Neurosci Lett 1989;100:29-34. [PubMed: 2761778]

WACHTEL SR, BENCSICS C, KANG UJ. Role of aromatic 1 -amino acid decarboxylase for dopamine replacement by genetically modified fibroblasts in a rat model of Parkinson's disease. J Neurochem 1997;69:2055-2063. [PubMed: 9349551]

WANG X, ZHANG G, SUN M, GELLER AI. General strategy for constructing large HSV-1 plasmid vectors that co-express multiple genes. Biotechniques 2001;31:204-212. [PubMed: 11464513]

WOOD MJ, BYRNES AP, PFAFF DW, RABKIN SD, CHARLTON HM. Inflammatory effects of gene transfer into the CNS with defective HSV-1 vectors. Gene Ther 1994;1:283-291. [PubMed: 7584093]

YADID G, HARVEY-WHITE JD, KOPIN IJ, GOLDSTEIN DS. Estimation of striatal dopamine spillover and metabolism in vivo. Neuroreport 2000;11:3367-3373. [PubMed: 11059904]

YAHR, M.D., and BERGMANN, K.J. (1987). Parkinson's Disease (Raven Press, New York).

YANG T, ZHANG G, ZHANG W, SUN M, WANG X, GELLER AI. Enhanced reporter gene expression in the rat brain from helper virus-free $\mathrm{HSV}-1$ vectors packaged in the presence of specific mutated HSV-1 proteins that affect the virion. Mol Brain Res 2001;90:1-16. [PubMed: 11376851]

YOSHIMOTO Y, LIN Q, COLLIER TJ, FRIM DM, BREAKE-FIELD XO, BOHN MC. Astrocytes retrovirally transduced with BDNF elicit behavioral improvement in a rat model of Parkinson's disease. Brain Res 1995;691:25-36. [PubMed: 8590062]

YUREK DM, SLADEK JR Jr. Dopamine cell replacement: Parkinson's disease. Annu Rev Neurosci 1990;13:415-440. [PubMed: 2183683]

ZHANG G, WANG X, YANG T, SUN M, ZHANG W, WANG Y, GELLER AI. A tyrosine hydroxylaseneurofilament chimeric promoter enhances long-term expression in rat forebrain neurons from helper virus-free HSV-1 vectors. Mol Brain Res 2000;84:17-31. [PubMed: 11113528]

ZHANG W, GELLER A. [Comparison of the immune response to gene transfer into the rat brain with helper or helper virus-free HSV-1 vectors]. Hua Xi Yi Ke Da Xue Xue Bao 2002;33:175-178. [PubMed: 12575177] 

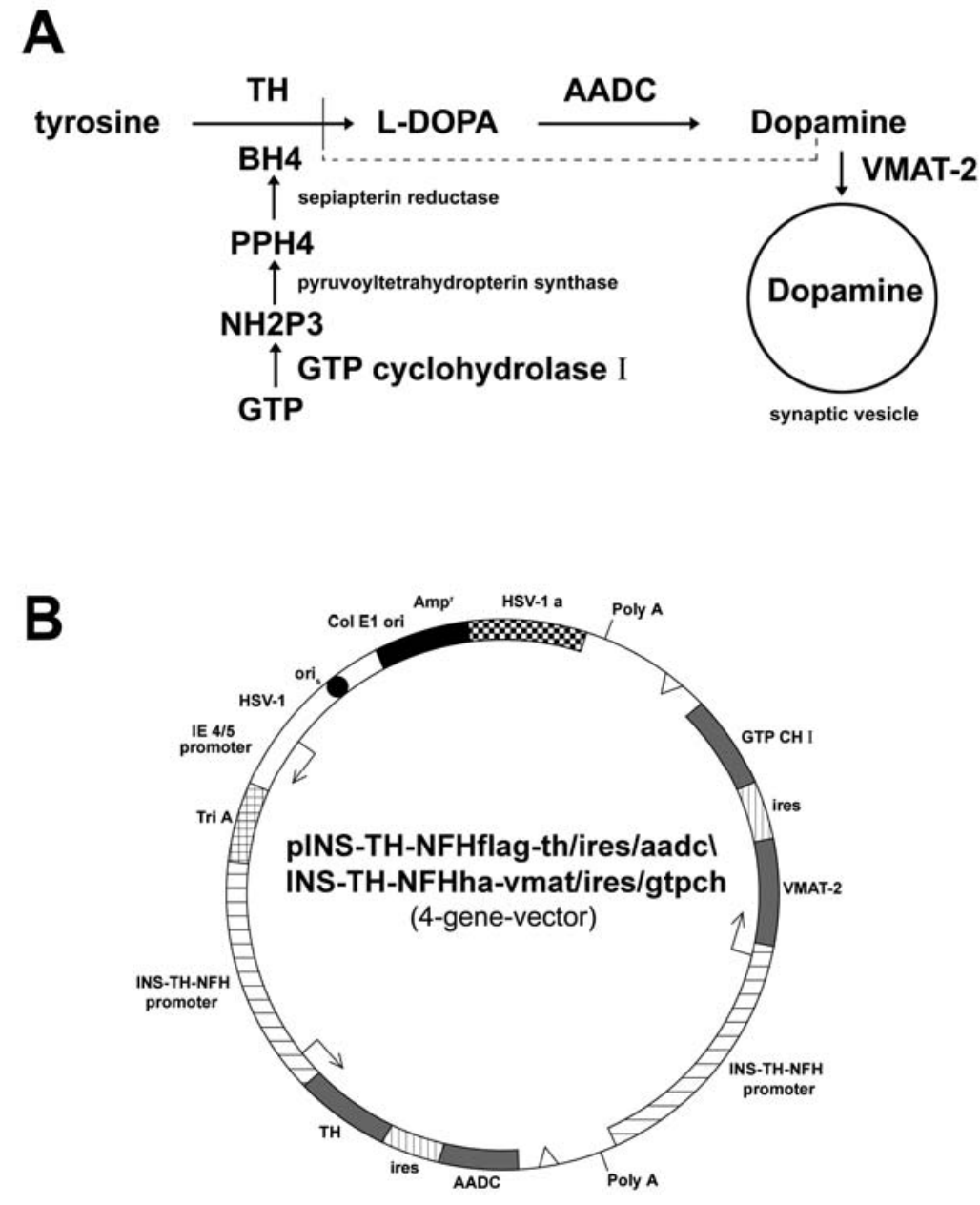

FIG. 1.

Schematic diagrams of the dopamine biosynthetic pathway and the 4-gene-vector. (A) The dopamine biosynthetic pathway. Tyro-sine hydroxylase $(\mathrm{TH})$ converts tyrosine to L-DOPA, and aromatic amino acid decarboxylase (AADC) converts L-DOPA to dopamine. Cytoplasmic dopamine feedback inhibits TH (dashed line). Vesicular monoamine transporter 2 (VMAT-2) transports dopamine into synaptic vesicles. The cofactor for $\mathrm{TH}$, tetrahydrobiopterin $\left(\mathrm{BH}_{4}\right)$, is synthesized in three steps: GTP cyclohydrolase I (GTP CH I) converts GTP to p-erythro-7,8dihydroneopterin triphosphate $\left(\mathrm{NH}_{2} \mathrm{P}_{3}\right) ; 6$-pyruvoyltetrahydropterin synthase produces 6pyruvoyltetrahydropterin $\left(\mathrm{PPH}_{4}\right)$; and sepiapterin reductase produces $\mathrm{BH}_{4}$. (B) The 4-genevector, pINS-TH-NFH- flag-th/ires/aadclINS-TH-NFHha-vmat/ires/gt-pch. An HSV-1 origin of DNA replication ( $\mathrm{ori}_{\mathrm{s}}$, solid circle) and an HSV-1 a sequence (contains the packaging site, checkered segment) support DNA replication and packaging into HSV-1 particles, respectively. The vector contains two transcription units: the first transcription unit contains the INS-TH-NFH promoter (horizontally hatched segment), FLAG-TH (gray segment), an IRES (vertically hatched segment), a human AADC cDNA (gray segment), and the second intron and polyadenylation site from the mouse $\beta$-globin gene (triangle and Poly A, respectively). The second transcription unit contains the INS-TH-NFH promoter, an HAVMAT-2 cDNA, an IRES, a human GTP CH I cDNA, and the second intron and polyadenylation site from the mouse $\beta$-globin gene. A cassette of three polyadenylation sites (cross-hatched segment) was inserted $3^{\prime}$ to the HSV-1 immediate-early (IE) $4 / 5$ promoter to 
reduce any effects this promoter might have on recombinant gene expression. Sequences from pBR322 (solid segment) were included to support propagation of the vector in E. coli. 

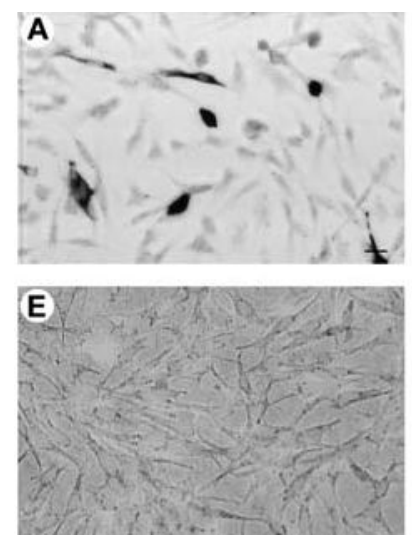
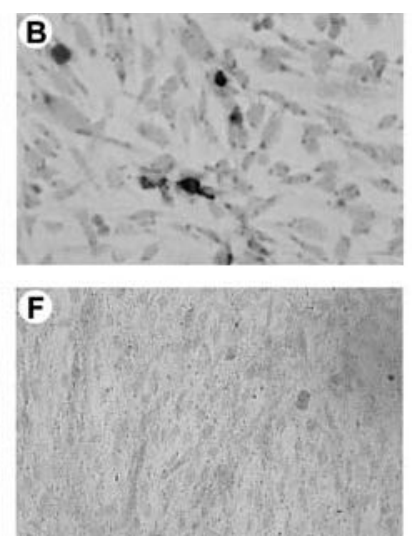
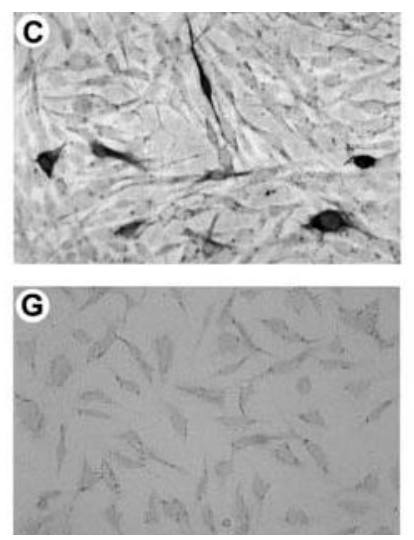
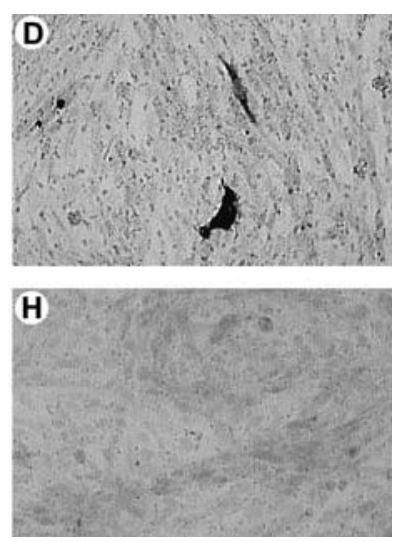

FIG. 2.

Immunocytochemistry performed on cultured BHK cells 1 day after infection with the 4-genevector, or mock infection. This TH contains the FLAG tag (FLAG-TH) and was detected with an anti-FLAG antibody, GTP CH I was detected with an anti-GTP CH I antibody, AADC was detected with an anti-human-specific AADC antibody, and this VMAT-2 contains the HA tag (HA-VMAT-2) and was detected with an anti-HA antibody. (A-D) The 4-gene-vector: (A) FLAG-IR, (B) GTP CH I-IR, (C) human AADC-IR, and (D) HA-IR. (E-H) Mock-infected cells: (E) FLAG-IR, (F) GTP CH I-IR, (G) human AADC-IR, and (H) HA-IR. Scale bar: 25 $\mu \mathrm{m}$. 

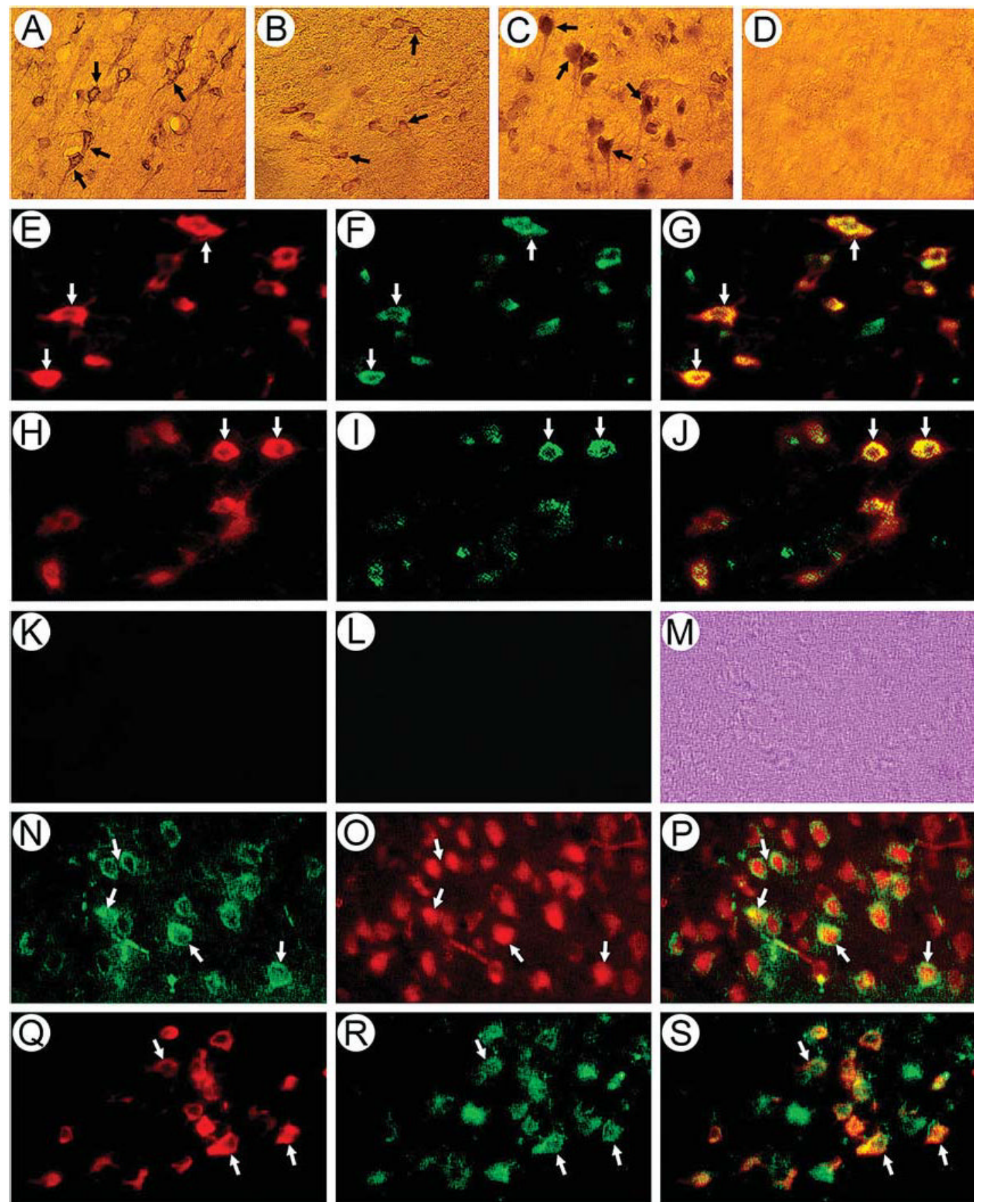

FIG. 3.

The 4-gene-vector supports expression of TH, AADC, and VMAT-2 in GABA-ergic striatal neurons in rats killed 4 days after gene transfer. (A-D) The 4-gene-vector supports expression of FLAG-TH, AADC, and HA-VMAT-2 in striatal cells; (A) FLAG-IR, (B) human AADCIR, and (C) HA-IR; (D) no FLAG-IR cells were observed in the contralateral, uninjected striatum. The arrows point to positive cells. $(\mathbf{E}-\mathbf{M})$ Gene products were colocalized to the same cells, using rhodamine- or fluorescein-conjugated secondary antibodies. (E-G) FLAG-TH and AADC are expressed in the same cells: (E) FLAG-IR, (F) human AADC-IR, and (G) costaining. (H-J) AADC and HA-VMAT-2 are expressed in the same cells: (H) human AADC-IR, (I) HAIR, and (J) costaining. (K-M) FLAG-TH and AADC are not expressed in 
the contralateral, uninjected striatum: (K) FLAG-IR, (L) human AADC-IR, and (M) a brightfield photomicrograph showing the cells in this section. $(\mathbf{N}-\mathbf{S})$ Recombinant gene products were localized to either neurons or GABA-ergic neurons, using antibodies against either NeuN or GAD, respectively. (N-P) AADC is expressed in neurons: (N) human AADC-IR, (O) NeuNIR, and (P) costaining. (Q-S) FLAG-TH is expressed in GABA-ergic neurons: (Q) FLAG-IR, (R) GAD-IR, and (S) costaining. Scale bar: $25 \mu \mathrm{m}$. 
5 months

$\mathrm{TH}$ (flag-IR)
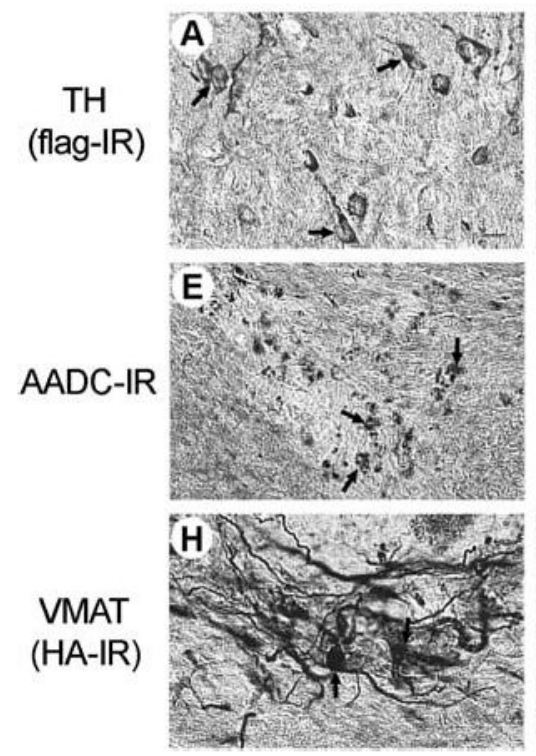

8 months

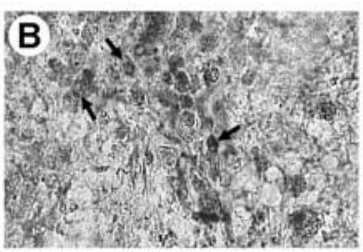

Not Done

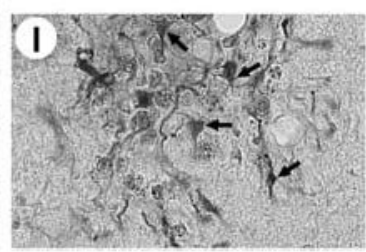

14 months
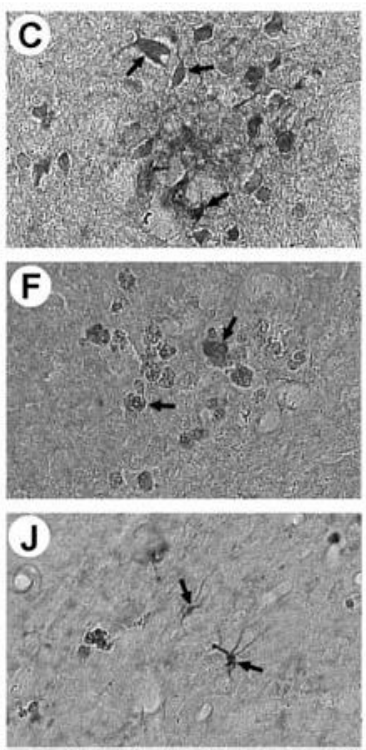

14 months, contralateral side
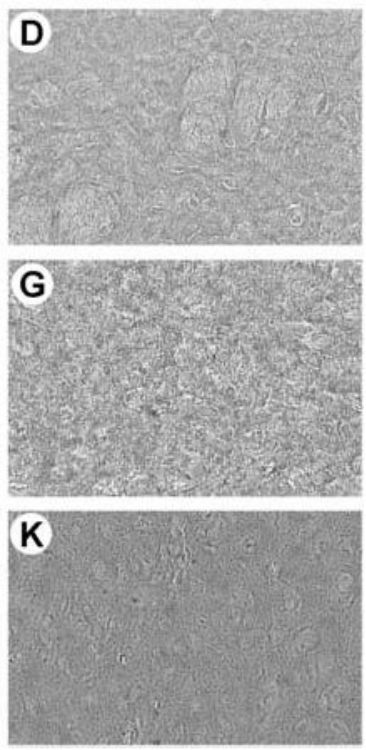

FIG. 4.

The 4-gene-vector supports long-term expression of TH, AADC, and VMAT-2 in the striatum. Rats that received the 4-gene-vector were killed 5, 8, or 14 months after gene transfer, and striatal cells containing FLAG-TH, human AADC, or HA-VMAT-2 were detected. The arrows point to positive cells. FLAG-IR and HA-IR filled the cell bodies and frequently extended into the proximal processes. AADC is the second gene in the flag-th/ires/aadc cassette, and the gene after the IRES in such cassettes is often expressed at a lower level compared with the first gene. Human AADC-IR staining was punctate and usually limited to the cell body. (A, E, and $\mathbf{H})$ A rat killed 5 months after gene transfer: (A) FLAG-IR, (E) human AADC-IR, and (H) HAIR. (B and I) A rat killed 8 months after gene transfer: (B) FLAG-IR and (I) HA-IR. (C, F, and J) A rat killed 14 months after gene transfer: (C) FLAG-IR, (F) human AADC-IR, and (J) HA-IR. (D, G, and $\mathbf{K})$ No recombinant gene products were detected in the contralateral striatum in a rat killed 14 months after gene transfer: (D) FLAG-IR, (G) human AADC-IR, and (K) HA-IR. Scale bar: $25 \mu \mathrm{m}$. 

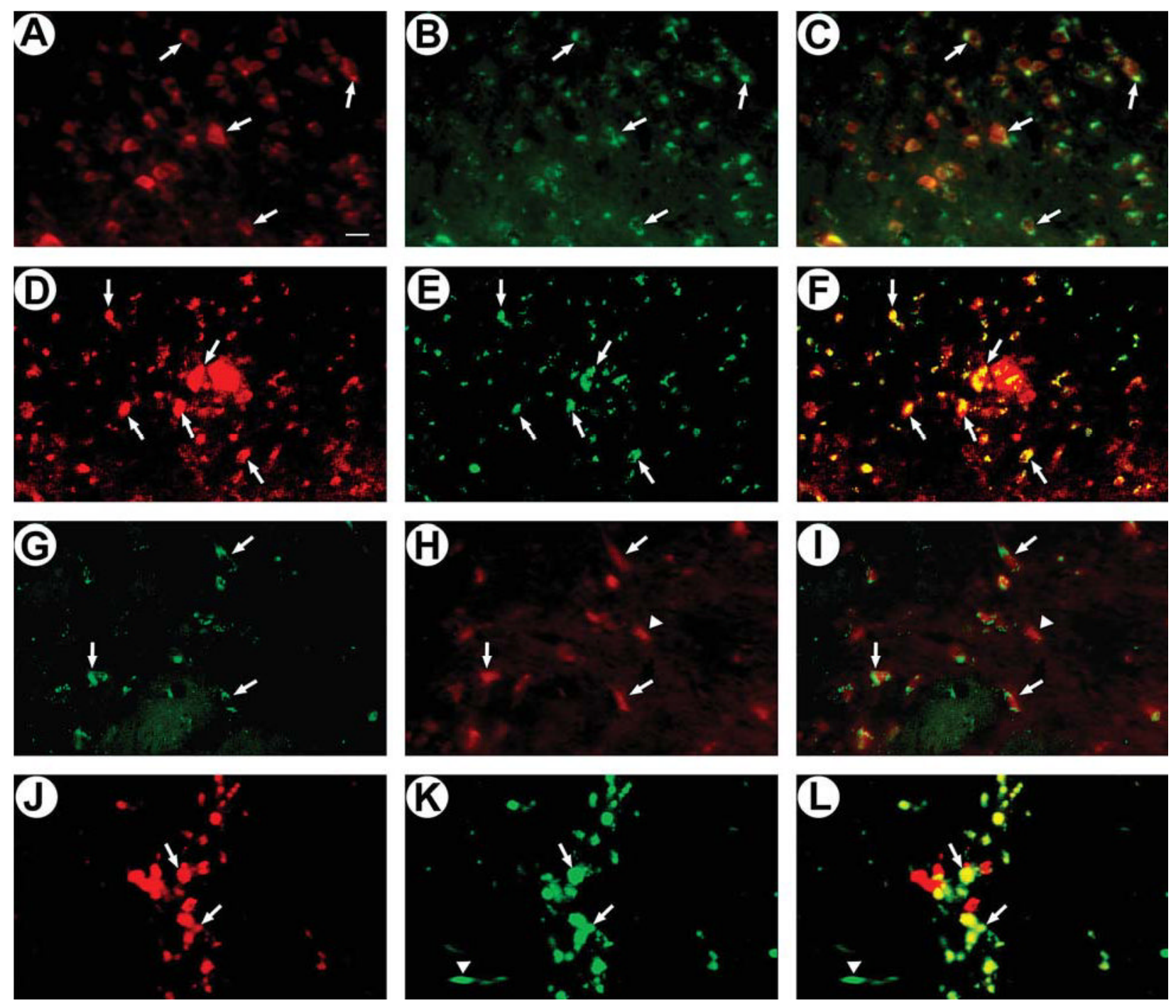

FIG. 5.

In a rat killed 14 months after gene transfer with the 4-gene-vector, FLAG-TH, human AADC, and HA-VMAT-2 were expressed in the same striatal cells, and human AADC was expressed in neurons; and in a rat killed 6 months after gene transfer, FLAG-TH was expressed in GABAergic neurons. The arrows point to positive cells. (A-C) FLAG-TH and AADC were expressed in the same cells: (A) FLAG-IR, (B) human AADC-IR, and (C) costaining. (D-F) AADC and HA-VMAT-2 were expressed in the same cells: (D) human AADC-IR, (E) HA-IR, and (F) costaining. (G-I) AADC was expressed in neurons: (G) human AADC-IR, $(\mathbf{H}) \mathrm{NeuN}$-IR, and (I) costaining. The arrowheads point to cells that contain the cell marker but lack recombinant gene expression. (J-L) FLAG-TH was expressed in GABA-ergic neurons: (J) FLAG-IR, (K) GAD-IR, and (L) costaining. Scale bar: $25 \mu \mathrm{m}$. 

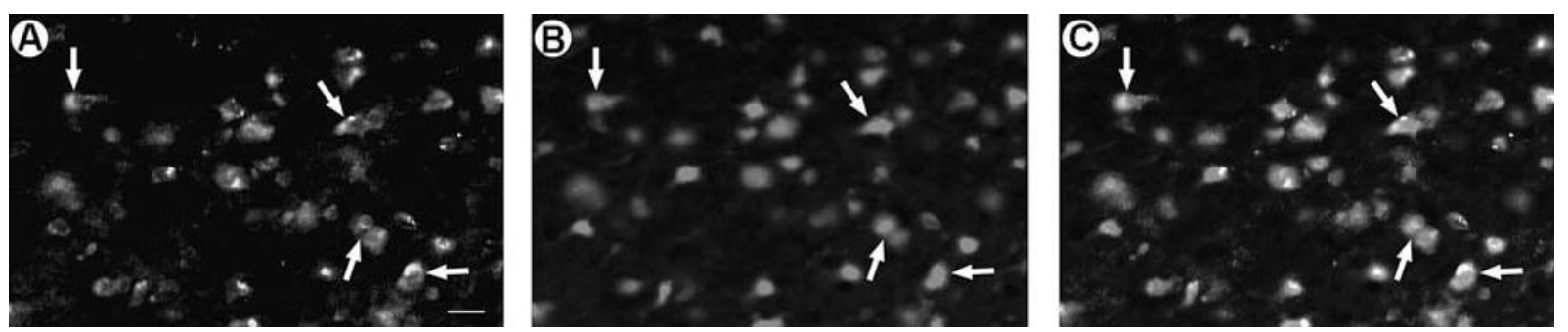

FIG. 6.

The lacZ-vector supported expression of $\beta$-Gal in the striatal neurons of a rat killed 7 weeks after gene transfer. (A-C) $\beta$-Gal was expressed in neurons: (A) $\beta$-Gal-IR, (B) NeuN-IR, and (C) costaining. The arrows point to positive cells. Scale bar: $25 \mu \mathrm{m}$. 

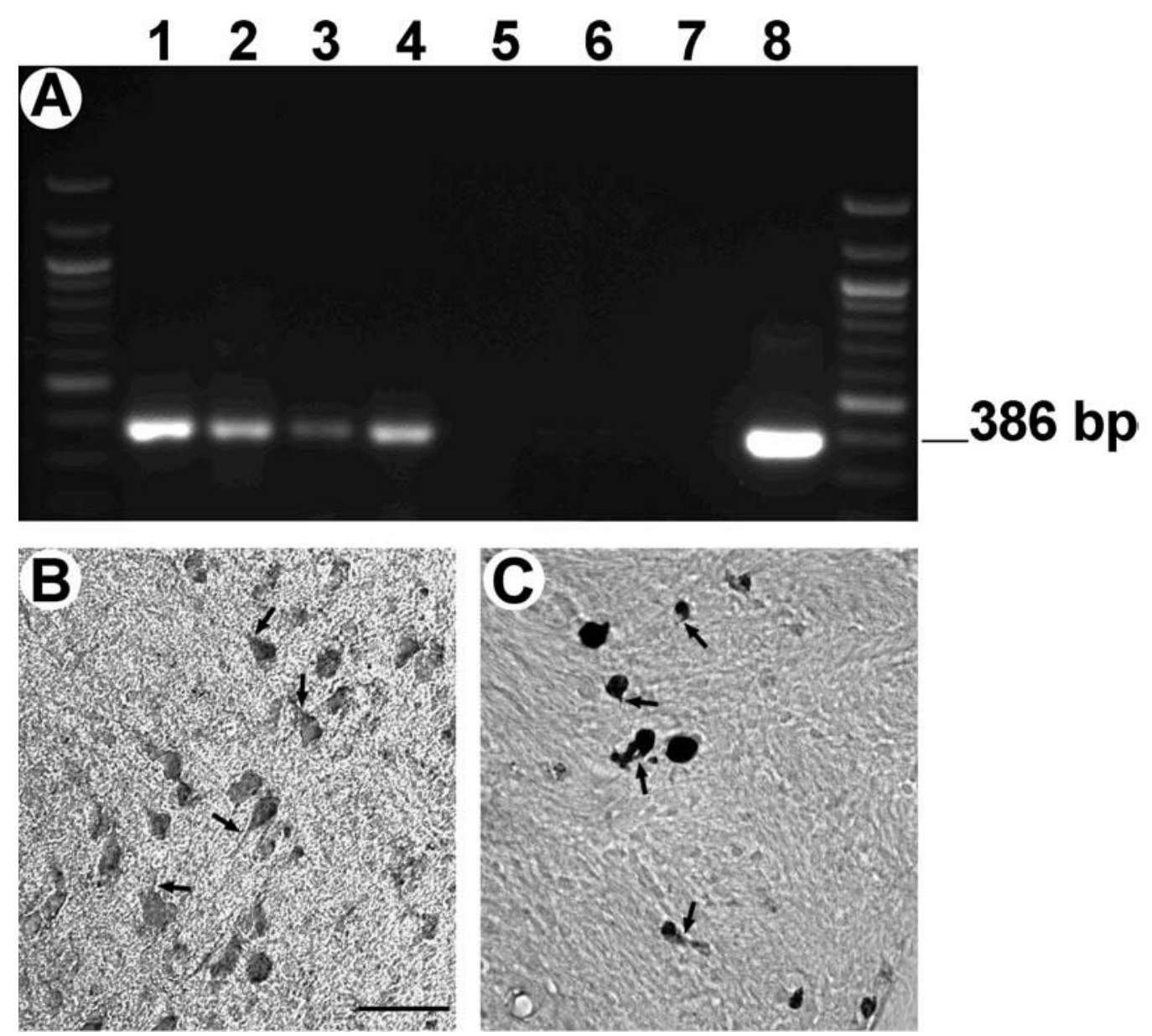

FIG. 7.

Long-term expression of recombinant, human GTP CH I RNA in the striatum of rats killed 4 days to 12 months after gene transfer with the 4-gene-vector, and GTP CH I-IR-positive striatal cells in rats killed either 4 days or 6 months after gene transfer. (A) Total RNA was isolated from striata, reverse transcription was performed with a primer from the human GTP CH I gene, and the reaction products were amplified by PCR, using the same primer and a second primer from the human GTP CH I gene. These primers are specific for the human GTP CH I gene and do not recognize the endogenous rat GTP CH I gene. The RT-PCR products are displayed on an agarose gel. The predicted size of the RT-PCR products is $386 \mathrm{bp}$. Lanes 1-4 used RNA samples from the striata of rats that received the 4-gene-vector and were killed 4 days, 1 month, 6 months, or 12 months after gene transfer, respectively. Lane 5, no RNA sample. Lane 6, RNA isolated from a striatum of a normal rat (no lesion, no gene transfer). Lane 7, reverse transcriptase was omitted from the reaction, and the reaction contained an aliquot of the same RNA preparation that was used in lane 1. Lane 8, 4-gene-vector plasmid DNA isolated from E. coli. (B and C) GTP CH I-IR-positive striatal cells, near the injection sites, from rats killed either (B) 4 days or (C) 6 months after gene transfer with the 4-genevector. The arrows point to positive cells that contain processes. Most of the GTP CH I-IR was in cell bodies, and because GTP CH I follows the IRES in the ha-vmat/ires/gtpch cassette, the levels of GTP CH I expression may be somewhat lower. Scale bar: $25 \mu \mathrm{m}$. 

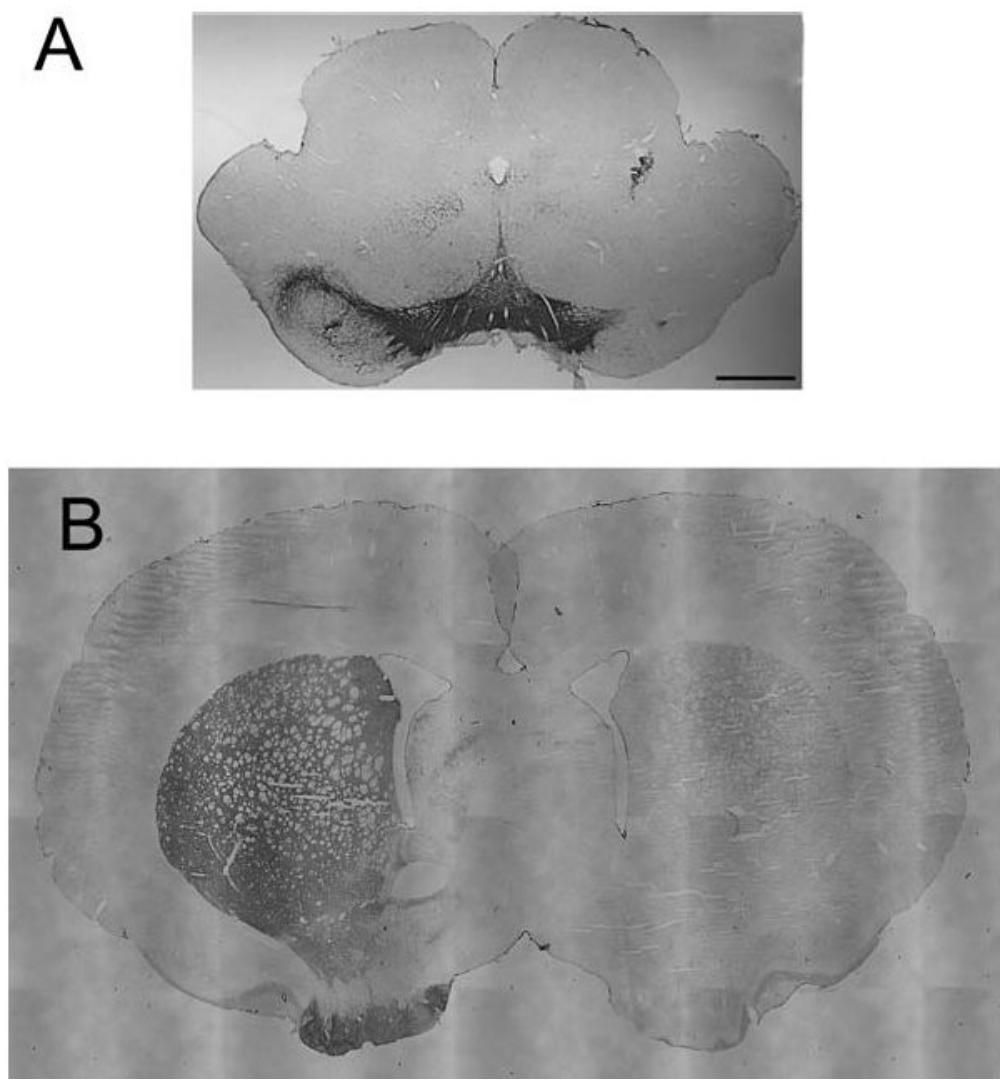

FIG. 8.

A 6-OHDA lesion ablates the vast majority of TH-IR cells in the substantia nigra pars compacta (SNc) and TH-IR fibers in the striatum. A rat was killed 1.5 months after lesioning with 6OHDA. Sections were stained with an antibody that recognizes rat TH. (A) A low-power view shows that the unlesioned, contralateral SNc contains numerous TH-IR-positive cells and processes, but that the lesioned SNc contains few TH-IR-positive cells and processes. (B) On the side contralateral to the lesion, the striatum contains a dense staining of TH-IR-positive processes, and this staining is not present in the ipsilateral, partially denervated, striatum. Scale bar: $1 \mathrm{~mm}$. 


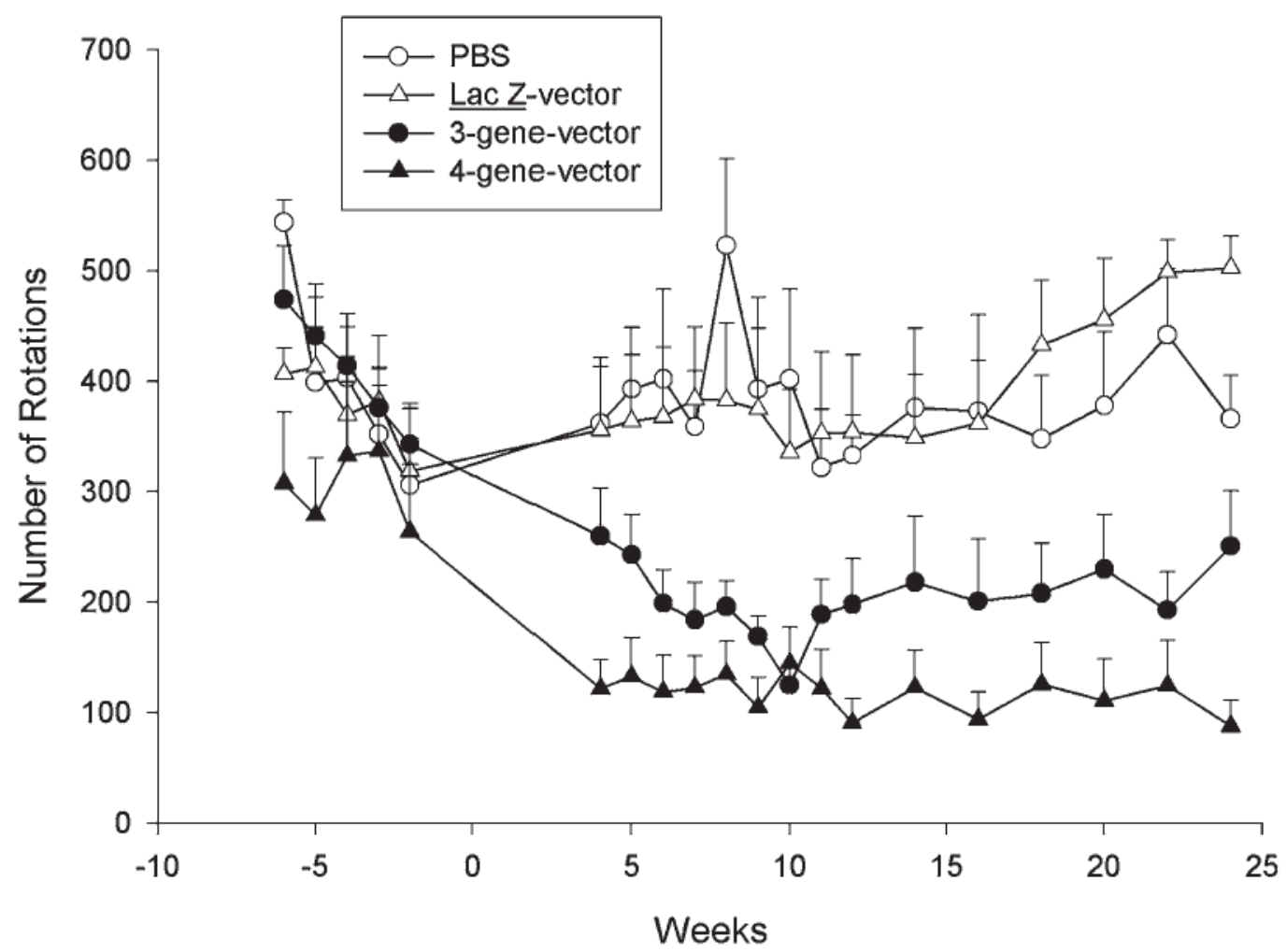

FIG. 9.

The 3-gene-vector and the 4-gene-vector support correction of apomorphine-induced rotational behavior in the 6-OHDA rat model of PD. Rats were lesioned with 6-OHDA. Starting 3 weeks later, the rats were tested three to five times, at weekly intervals, for apomorphine-induced rotational behavior. Rats with relatively complete lesions (an average of five or more rotations per minute during the 15- to 20-min interval after apomorphine injection) were used for gene transfer; these rats received the 3-gene-vector, the 4-gene-vector, the lacZ-vector, or PBS. Starting 3 weeks after gene transfer, the rats were tested for apomorphine-induced rotational behavior each week for 2 months, and then every other week until they were killed. The values shown represent the number of rotations per rat for each group at each time point, for the 60min period after injection of apomorphine (mean \pm SEM; 3-gene-vector, $n=11$ rats; 4-genevector, $n=10$ rats; lacZ-vector, $n=10$ rats; and PBS, $n=6$ rats). 

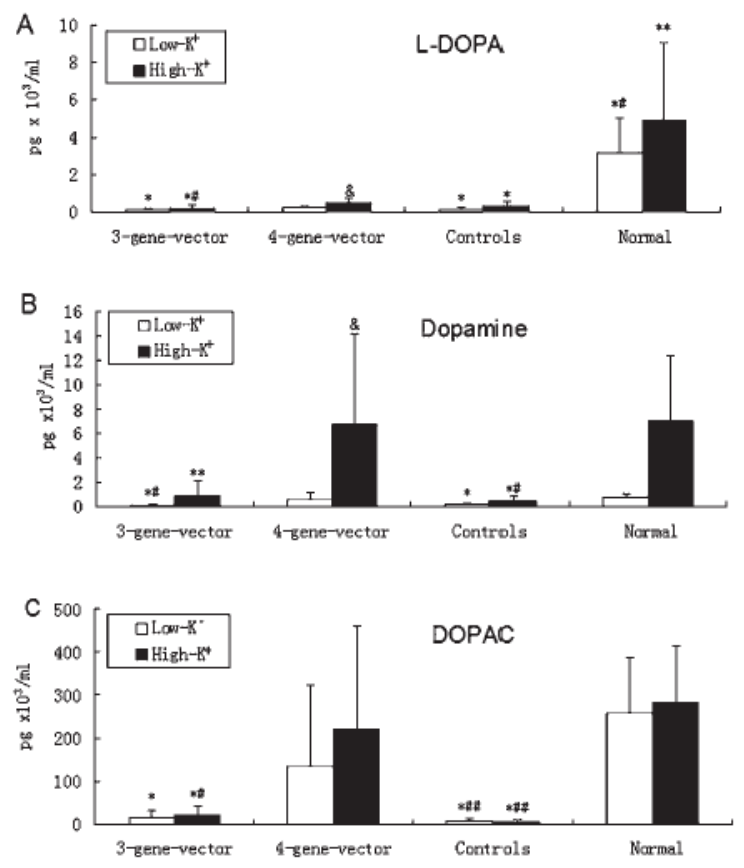

FIG. 10.

Extracellular striatal levels of catecholamines, measured by in vivo microdialysis, at an average of 3 months after gene transfer with the 3-gene-vector, or the 4-gene-vector, or controls. Dialysates were collected by perfusion with artificial CSF containing low $\mathrm{K}^{+}(2.7 \mathrm{mM})$ followed by artificial CSF containing high $\mathrm{K}^{+}(56 \mathrm{mM})$. The levels of L-DOPA, dopa-mine, and DOPAC in each sample were determined by HPLC with electrochemical detection (Holmes et al., 1994; Yadid et al., 2000). The mean \pm SEM ( $\left.\mathrm{pg} \times 10^{3} / \mathrm{ml}\right)$ of $\mathrm{L}-\mathrm{DOPA}$, dopamine, and DOPAC, under low $\mathrm{K}^{+}$(open columns) or high $\mathrm{K}^{+}$(solid columns) conditions, are shown for the 3-gene-vector ( $n=8$ rats), the 4-gene-vector ( $n=7$ rats), the control (6OHDA lesion, lacZ-vector, or PBS; $n=8$ rats), and normal groups (unlesioned, no gene transfer; $n=5$ rats). The asterisks $(*)$ and pound signs (\#) indicate statistically significant differences (ANOVA) compared with the 4-gene-vector and the same condition (low $\mathrm{K}^{+}$or high $\left.\mathrm{K}^{+}\right): * p<0.05, * * p<0.02$, ${ }^{* \#} p<0.01$, and ${ }^{* \# \#} p<0.001$. Comparing the low $\mathrm{K}^{+}$and high $\mathrm{K}^{+}$conditions: With high $\mathrm{K}^{+}$treatment, the 4-gene-vector, but not the 3-gene-vector, supported a $1200 \%$ increase in the levels of extracellular dopamine (low $\mathrm{K}^{+}$versus high $\mathrm{K}^{+}$: 3-genevector, $p>0.05$; 4 -gene-vector, ${ }^{\&} p<0.05$ ), a modest $200 \%$ increase in the low levels of ${ }_{\mathrm{L}}$-DOPA $\left({ }^{\&} p<0.05\right)$, and did not increase the levels of DOPAC $(p>0.05)$. 


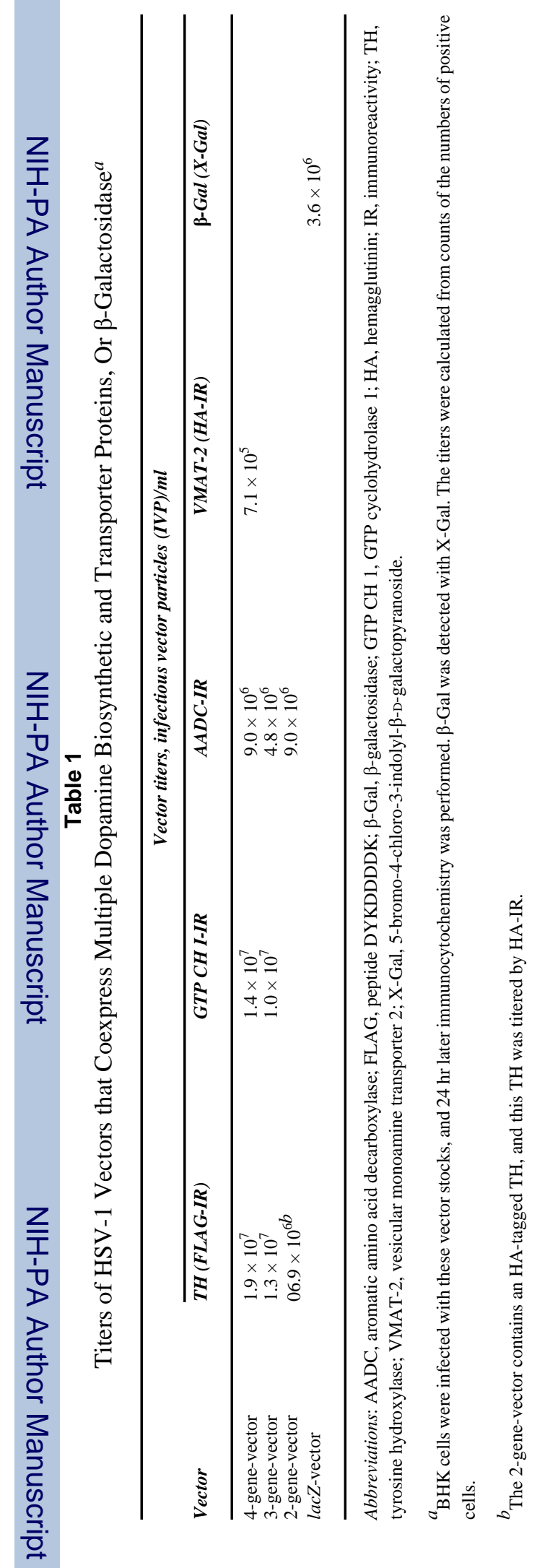


SUN et al.

Page 34

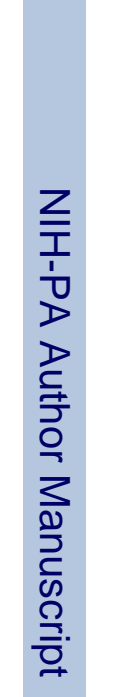

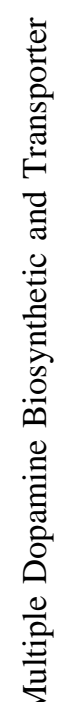

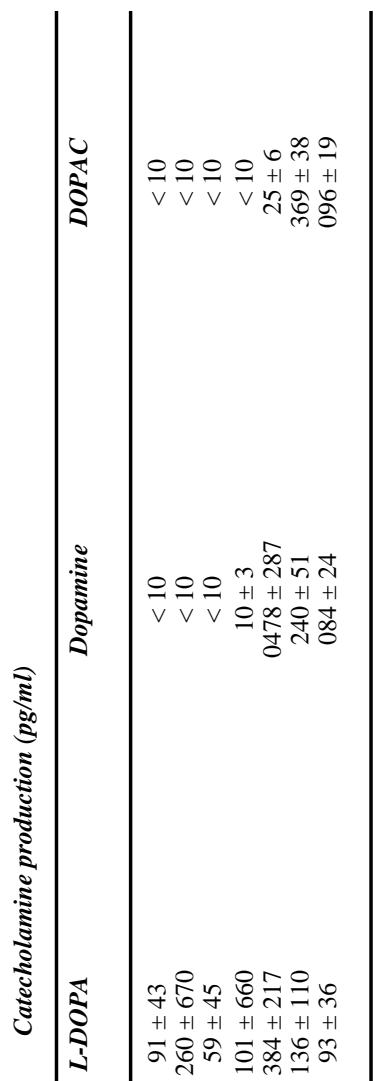

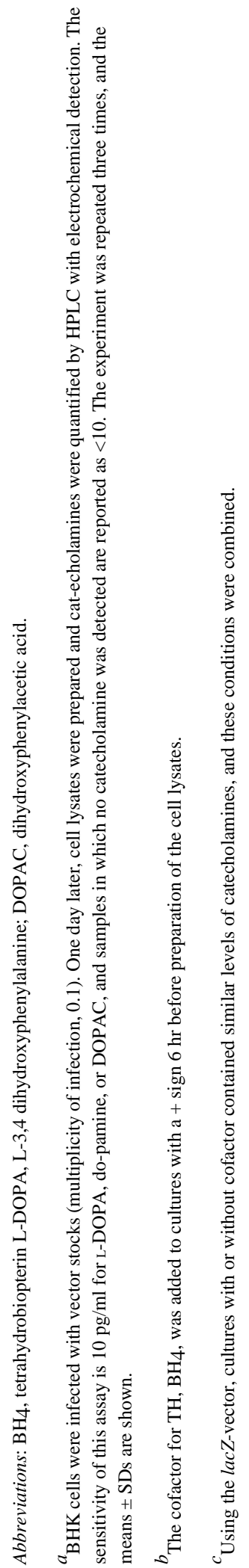

Hum Gene Ther. Author manuscript; available in PMC 2008 November 10. 
娄

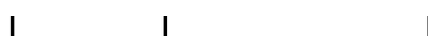

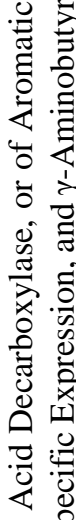
气ั๊

|

$\stackrel{2}{0}$

-

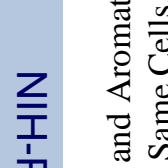

>0口

$>\frac{0}{2}$

产它递 